\title{
The social-ecological dimensions of changing global freshwater availability
}

This is a non-peer reviewed preprint submitted to EarthArXiv which is in review at "Nature".

Xander Huggins ${ }^{1,2}$, Tom Gleeson ${ }^{1,3^{*}}$, Matti Kummu ${ }^{4}$, Samuel C Zipper ${ }^{5}$, Tara Troy ${ }^{1}$, Yoshihide Wada $^{6}$, James S. Famiglietti ${ }^{2,7,8}$

* correspondence to tgleeson@uvic.ca

\author{
Affiliations: \\ ${ }^{1}$ Department of Civil Engineering, University of Victoria, Victoria, BC, Canada, \\ ${ }^{2}$ Global Institute for Water Security, University of Saskatchewan, Saskatoon, SK, Canada, \\ ${ }^{3}$ School of Earth and Ocean Sciences, University of Victoria, Victoria, BC, Canada \\ ${ }^{4}$ Water and Development Research Group, Aalto University, Espoo, Finland \\ ${ }^{5}$ Kansas Geological Survey, University of Kansas, Lawrence, KS, USA \\ ${ }^{6}$ International Institute for Applied Systems Analysis, Laxenburg, Austria \\ ${ }^{7}$ School of Environment and Sustainability, University of Saskatchewan, Saskatoon, SK, Canada \\ ${ }^{8}$ Department of Geography and Planning, University of Saskatchewan, Saskatoon, SK, Canada
}

\section{Summary paragraph:}

Quantifying physical water security at the global scale remains hampered by a lack of systematically produced observational data. Here we combine the observed trends in global freshwater availability from the recently completed Gravity Recovery and Climate Experiment satellite mission ${ }^{1}$ with more than a dozen other global datasets and provide the missing observational basis to numerous existing perceptions of global water security. We find the disparity between the water 'haves' and 'have nots' of the world continues to widen ${ }^{2}$. Nearly one in two people who live in areas of extreme water shortage experienced drying over the 14-year observation period while a fifth of crop calories produced for human food are grown in regions that dried yet already suffer from water shortage. The global water availability trends reveal a clear human imprint ${ }^{1}$ and reflect a world-wide inability to manage water resources for long term water security. We identify 21 regions that stand to face especially high social-ecological system pressures from the water availability trends and assess flooding and water scarcity vulnerability at the global scale. This application of remotely sensed water availability trends contributes to the quantitative diagnosis of the world's contemporary water security challenges that will be useful in global policy directive setting.

\section{Main text:}

Sufficient and timely freshwater of suitable quality is essential for the health of societies and ecosystems ${ }^{3-7}$. The volume, state, and quality of water at a given time and location are determined primarily by global hydrological and biogeochemical cycle processes, although human activity is increasingly dominating water availability and quality at local to global scales ${ }^{8-10}$. This dependence of humans and the broader biophysical environment on freshwater is reflected in the inclusion of 'freshwater use' as one of the nine planetary boundaries ${ }^{11,12}$ and in the dedication of UN Sustainable Development Goal 6: Ensure availability and sustainable management of water and sanitation for all. Despite this broad consensus on freshwater's global importance for 
sustainable development and in preserving Earth System functions that support livable conditions for society, our understanding of physical global water security remains relatively limited.

Water security is often defined as the suitable access to adequate water quality and quantity to ensure human and ecosystem health ${ }^{13}$. In recognition of the increasing interdependency between water resources and human society, understanding water security through the social-ecological system framework has been suggested as a robust approach to consider the interlinked system dynamics between human society and the biophysical world e.g. 14-17. This framework to analyze 'economies in societies in nature' 18 highlights the interactions between governance systems, actors, and resources in the context of existing social, economic, and political settings that together govern overall system outcomes ${ }^{19}$ such as the water security of a nation, region, or world. Varis et al. ${ }^{14}$ apply the social-ecological systems framework to a global analysis of river basin resilience, however the framework remains to be applied explicitly in global water security analysis. While moving beyond 'water-centric' formulations of water security, it is also increasingly important to frame hydrological observations in broad contexts that enable inter- and transdisciplinary understanding and cooperation between actors consistent with the inter- and transdisciplinary nature of water itself.

Existing studies of global water security are based on water availability datasets produced by global computer models e.g. 20,21 , some of which rely on sparse point observations ${ }^{\text {e.g. } 22-24}$, and are each constrained by non-trivial assumptions that yield uncertainty (e.g. see ref. ${ }^{25}$ ). These studies, which cover a wide range of temporal and spatial scales e.g. 26,27, include physical metrics (e.g. the water crowding index ${ }^{28}$, the water to availability ratio $^{29}$, the groundwater footprint ${ }^{30}$ ), simple composite indices that combine physical metrics with at least one social parameter (e.g. the social water stress index ${ }^{31}$ ), and multiple criteria assessments that by definition consider a wider array of physical and social parameters ${ }^{\text {e.g. }}{ }^{32-35}$. As a result, our understanding of global water security hinges on the collective validity of hydrological models. To ensure a correct diagnosis of the world's contemporary water security issues, and thus to help direct critical human and technical resources to the most pressing water challenges, globally consistent, systematically collected observational data should increasingly be leveraged to supplement and verify conclusions drawn from model-based studies.

From 2002-2017, the Gravity Recovery and Climate Experiment (GRACE) satellite mission tracked variations in Earth's gravity field and these variations can be reduced to anomalies in terrestrial water storage (TWS) once glacial isostatic adjustment signals are removed ${ }^{36}$. TWS is an aggregate measure of water storage and includes groundwater, soil moisture, surface water, ice and snow storages. While absolute TWS measurements cannot be derived from the GRACE observations, trends in the TWS anomalies have provided the first observational dataset of the changing global hydrological landscape (see Data sources for discussion on GRACE TWS trend uncertainty). Rodell et al. ${ }^{1}$ synthesized these TWS anomalies over the April 2002 - March 2016 time period, interpreted the trends to represent emerging trends in freshwater availability ${ }^{1}$ (Fig. 1a) and attributed 34 distinct regional storage trends to climate change, human impact, or natural variability (Fig. 1b). Climate change is attributed to the severe losses in high-latitude glaciers, ice sheets, and to the high-latitude precipitation increases in North America and Eurasia which are consistent with Intergovernmental Panel on Climate Change model predictions ${ }^{1}$. Human impacts are directly attributed to mid-latitude drying trends driven by unsustainable groundwater use and water accumulation from large dam projects. Further, global human activity is the principal driver 
of climate change and is thus additionally implicated in the climate change attributed storage trends. Natural variability, which is subject to the changing climate, is attributed to storage trends produced from oscillations between wet and dry periods, and natural droughts which may not persist beyond the relatively short GRACE observation period. The fading of these natural variability trends may drive subsequent changes in human behaviour and associated TWS trends, however when, how and where these behavioral shifts would occur remains unclear. These pioneering observations have been used to assess the reliability of global hydrological and land surface models ${ }^{25}$ and to derive important hydrological insights at the basin, aquifer, or regional

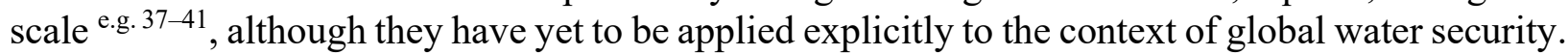

Here, we quantify the social-ecological system implications of the GRACE-observed TWS trends in the context of global water security for the first time. We accomplish this through two main analyses: (1) social-ecological dimensions analyses to isolate and spatially locate regions exposed to high social-ecological system pressures arising from the observed water storage trends, and (2) vulnerability analyses that integrate the storage trends with hazard datasets of water shortage and flooding occurrence. Through this work, we provide previously missing observational evidence to substantiate many existing perceptions of global water security. For simplicity, we refer hereafter to TWS losing trends as drying, TWS gaining trends as wetting, and TWS trends, generally, as water availability trends ${ }^{1}$. Further, trends with magnitudes $\geq 2 \mathrm{cmyr}^{-1}$ are described as severe which is consistent with the graphical representation of GRACE TWS trends in the literature e.g.1,42.

\section{$\underline{\text { Social-ecological dimensions }}$}

Global hydrological studies increasingly incorporate human activity to determine the disturbance that humans impart on water resources, however this perspective is rarely inverted to systematically consider the implications of changing water resources on humans. Here, we analyze the distribution of water availability trends against four core social-ecological system dimensions at the global scale: the human population (Fig. 2a,b), agricultural activity (Fig. 2c,d), economic activity (Fig. 2e,f), and critical ecological areas (Fig. 2g,h). These dimensions are selected as they coincide with the commonly used domestic, agricultural, industrial, and environmental sectors considered in physical water scarcity assessments ${ }^{43}$ and the social, economic, and environmental pillars of sustainability.

We begin with the human population and find that 20-times more people live in regions that underwent severe drying (359 million) than in regions that experienced severe wetting (18 million) over the GRACE observation period (Fig. 2a). While half of the global population (3.66 billion, 51\%) live in regions that maintained relatively constant water availability (magnitudes $\leq$ $0.5 \mathrm{cmyr}^{-1}$ ), these extremes accentuate a negatively skewed population distribution relative to water availability trends. Densely populated and drying regions are found around the North China Plain, northern and eastern India, southern Caucasia and northwestern Iran, while the densely populated wetting regions are found in the Okavango and Zambezi Basins, the Nile Headwaters, tropical western Africa, and in eastern central China where the Three Gorges Dam among other reservoirs filled (Fig. 2b). Human susceptibility to changes in water availability, however, also largely depends on prior water availability which is not considered in the water storage trends alone. We thus incorporate a global assessment of water shortage (water availability per capita per year) to provide this necessary context to the water availability trends. It is through this process 
that emergent water availability inequalities are highlighted. Of the 1.9 billion living in regions of clear drying (drying at least $\left.0.5 \mathrm{cmyr}^{-1}\right)$, fully $75 \%$ already experience water shortage $(<1700$ $\left.\mathrm{m}^{3} \mathrm{cap}^{-1} \mathrm{yr}^{-1}\right)$. Nearly one in two people $(46 \%)$ living in extreme water shortage $\left(<500 \mathrm{~m}^{3} \mathrm{cap}^{-1} \mathrm{yr}^{-}\right.$ ${ }^{1}$ ) experienced clear declines in water availability while only $15 \%$ of those living in conditions of no water shortage $\left(\geq 1700 \mathrm{~m}^{3} \mathrm{cap}^{-1} \mathrm{yr}^{-1}\right)$ dried at similar rates (Supplementary Table 1). This uneven impact of water storage loss, that disproportionately affects the water poor, is clear evidence that the disparity between the water 'haves' and 'have nots' of the world continues to widen ${ }^{2}$. Further, it is clear indication that these water scarce populations, likely out of necessity, turn to nonrenewable water sources (e.g. groundwater consumption beyond physically sustainable limits) to supply their immediate water demands in exchange for reduced long term water security.

Agricultural activity represents humankind's largest use and consumption of freshwater ${ }^{44}$ and is generally recognized as the most significant direct influence humans exert on the hydrologic cycle. Accordingly, the GRACE TWS trends show evidence of a clear agricultural imprint. Alarmingly, a fifth $(20 \%)$ of all calories produced for human food are cultivated in regions that experienced clear drying trends and are in regions of existing water shortage. Conversely, only a tenth $(10 \%)$ of calories produced for animal feed and non-food uses (e.g. biofuels) face similar conditions (Fig. 2c, Supplementary Tables 2,3). Severe drying trends are found at the greatest relative frequency in heavily irrigated regions with high cropland density (Supplementary Fig. 1a). These regions are predominantly dependent on groundwater for irrigation (Supplementary Fig. 1b), possess calorie yields among the highest in the world (Supplementary Fig. 1c), and overwhelmingly produce crops for human food (Supplementary Fig. 1d). Thus, crops produced for human consumption are driving unsustainable water use and are consequently most threatened by declines in water availability. While crop selection can alter evapotranspiration rates relative to natural vegetation, the direction of this impact is not globally uniform ${ }^{43}$. Thus, we argue these observations reinforce the modelled finding that unsustainable groundwater pumping is sustaining global irrigation practices ${ }^{45}$. The agriculturally active and drying regions of the world are numerous, and often align with large aquifer systems ${ }^{40}$, which provide further evidence that agricultural activity is being sustained by groundwater depletion. These regions (and underlying aquifers) include: the Californian Central Valley (Californian Central Valley Aquifer System), the southern Great Plains of North America (Ogallala Aquifer), the Argentinian pampas, the Ukrainian and Russian borderlands (Russian Platform Basins), southern Caucasia and northwestern Iran, northern and eastern India (Indus and Ganges-Brahmaputra Basins), and the North China Plain (North China Aquifer System). Similarly productive yet wetting regions are fewer in number: the northern Great Plains of North America (Northern Great Plains Aquifer), southern Brazil (Guarani Aquifer System), and eastern central China (Fig. 2d). The bias towards human caused drying in the world's food baskets reinforces the need for these regions to develop diverse adaptation strategies, and their predicaments underscore the difficulty of satisfying food security and water security interests simultaneously ${ }^{28,46}$.

To identify how economic activity is situated relative to the water availability trends, we consider the global economy as we did for the human population and agricultural activity. Economic wealth contributes to a region's coping capacity yet also identifies the extent of economic activity that can be exposed to potential harms ${ }^{47}$. The economic implications of severe freshwater trends will be most acute in economies dependent on water intensive activities (e.g. energy production; paper and chemical industries; the agricultural sector). However, in absence of a water-dependent global economic activity dataset we use Gross Domestic Product (GDP) at 
purchasing power parity (2011 int. USD) with this caveat. We find concentrations of economic activity that experienced severe drying in California, northern and eastern India, and northern China, and a concentration of economic activity that experienced strong wetting in eastern central China (Fig. 2f). That many of these regions are also agriculturally active (see Fig. 2d) suggests that these economies are likely sensitive to the water storage trends. Further, when the freshwater availability trends are mapped against GDP per capita, we find eastern Brazil, the Okavango and Zambezi Basins, the Nile headwaters, and northern and eastern India to emerge as the most economically limited populations experiencing strong water availability trends (Supplementary Fig. 2). That regions in northern and eastern India possess high total GDP yet low GDP per capita highlights the exceptional economic and social challenges these regions face in confronting severe drying conditions. Overall, we observe less 'hotspots' in this economic analysis relative to the population and calorie analyses as GDP is found to concentrate in regions of 'stable' water storages $\left(\sigma=0.82 \mathrm{cmyr}^{-1}, \mu=-0.08 \mathrm{cmyr}^{-1}\right)$ relative to the population $\left(\sigma=1.00 \mathrm{cmyr}^{-1}, \mu=-0.16 \mathrm{cmyr}^{-1}\right)$ distribution (Fig. 2e). While the role economic strength plays in controlling aggregate water availability remains under addressed at the global scale, our finding that economic strength does not exist to the same degree as the human population in severe drying regions suggests these areas may have reduced coping capacity in the face of increasing water scarcity. Overall, these patterns underscore an important challenge: regions of economic strength are not coincident with the hydrologically dynamic regions of the world where such resilience capacity is most needed.

Ecological activity and human society form interdependent systems with one critical manifestation being their shared dependence on water. To emphasize the critical need for ecological considerations in global water security, particularly in the Anthropocene, we incorporate an ecological dimension to our analysis. Terrestrial water fulfills myriad roles in support of ecosystem processes, such as providing flows that sustain freshwater and estuarine ecosystems ${ }^{4}$ and providing water for vegetation uptake, which in turn provide myriad ecosystem services to society. To broadly incorporate ecological considerations, we combine three global datasets to assess the prioritization and water sensitivity of ecological regions against the water availability trends. We rely on the Global 200 list of priority ecoregions for global conservation ${ }^{48}$ to indicate region prioritization, and global datasets of vegetation sensitivity to soil moisture availability $^{49}$, and environmental flow sensitivity to groundwater head decline ${ }^{50}$ to indicate water availability sensitivity (see Data sources). We combine these datasets in a single indicator of ecological priority and water sensitivity (see Methods) and evaluate this indicator against the global water availability trends (Fig. 2h). We find the trinity of prioritization, water sensitivity, and strong water availability trends in the Gulf of Alaska Coastal Rivers (drying), Pacific Coastal Rivers and Streams (drying), Northern Prairie (wetting), Amazon River and Flooded Forests (wetting), Upper Paraná Rivers and Streams (wetting), Atlantic Forest of Brazil (drying), Middle Asian Montane Steppe and Woodlands (drying), Naga-Manupuri-Chin Hills Moist Forests (drying), and Yangtze River and Lakes (wetting) ecoregions. The Gulf of Alaska Coastal Rivers ecoregion is drying at the fastest rate of any ecoregion in the world (Fig. $2 \mathrm{~g}$ ) and coincides with climate change attributed glacier retreat ${ }^{1}$. Glacial retreat in regions around the world influences regional flow regimes in the form of increased flows from greater meltwater generation in the short term, and streamflow reductions, particularly in low flow summer months where glacial melt typically sustains baseflow, in the long term ${ }^{51}$. These flow regime changes, if they occur faster than local ecosystems can adapt, could threaten long-term ecosystem health and viability ${ }^{52}$. That the world's critical ecological regions are confronting similar challenges in global freshwater 
availability trends underscores the need to address these issues equitably and cohesively in solutions aimed at addressing the challenges the trends pose to humanity.

To gauge overall social-ecological system exposure to the freshwater availability trends, we combine the individual dimensions analyzed (population, agricultural, economic, and ecological) into a single indicator. This process yields a filtered version of the original water availability trends map (i.e. Fig. 1a) that highlights the critical social-ecological regions of the changing global freshwater landscape (Fig. 3a). We then isolate the highly exposed regions of the world based on collective social-ecological system exposure and assess their adaptive capacity. Isolating the top 5\% of areas (excluding Antarctica and Greenland) based on this collective exposure yields 21 regions that stand to face the greatest social-ecological system pressures from the water availability trends (Fig. 3b). These areas encompass $23 \%$ of the global population, $20 \%$ of global caloric crop production, and $18 \%$ of global GDP at purchasing power parity. Adaptive capacity, as defined by Varis et al. ${ }^{14}$, represents the ability of the social-ecological system to 'respond to disturbances' and 'implement adaptation strategies to cope with current or future events', and is based on indicators of government effectiveness, GDP per capita, and human development. Combining social-ecological system pressures with adaptive capacity is helpful in demonstrating the markedly different scenarios confronting societies around the world facing similar water availability pressures. For instance, the drying in California's Central Valley is comparable to that of eastern India yet the adaptive capacities of the two regions are markedly different. A similar juxtaposition can be drawn between the wetting of the northern Great Plains of North America and the wetting experienced in the Okavango and Zambezi Basins. We characterize low and high adaptive capacity based on population-weighted $20^{\text {th }}$ and $80^{\text {th }}$ percentiles and find high adaptive capacity to characterize North American and Saudi Arabian regions and to partially characterize regions in central Argentina and in the North China Plain. Conversely, we find low adaptive capacity to characterize regions in Sub-Saharan Africa and Syria, and to partially characterize regions in eastern India and Central America (all remaining regions are characterized by moderate adaptive capacity). While the quantification of adaptive capacity is preliminary, particularly when performed at the global scale, we argue that including this context is crucial to understanding the varied and more-than-physical challenges presented by water security goals.

\section{$\underline{\text { Physical water security vulnerability }}$}

The above described social-ecological dimensions of changing freshwater availability are helpful in understanding the evolving relationships between these critical sectors with water, yet the trends alone cannot characterize a region's susceptibility to water resource hazards. However, combining these trends with existing levels of quantitative hazards, such as water scarcity or flooding, can more accurately portray the developing nature of water resources concerns. For instance, populations living in areas of high water shortage will likely experience the impacts of severe drying trends more acutely than populations living in areas of no water shortage. Conversely, a region that experiences frequent flooding will generally be more sensitive to wetting trends than a region which is not prone to flooding. To address this limitation, we spatially assess the water availability trends against hazard levels of flooding (Fig. 4a) and water shortage (Fig. $4 b)$ evaluated near the onset of the GRACE mission. Wetting trends in flood prone areas are found in the Northern Triangle of Central America, central Ethiopia, central India, Vietnam, and southeastern China. Conversely, drying trends exacerbating high water shortages are found in the 
American southwest, throughout the Middle East (Syria, Jordan, Saudi Arabia, Iraq, Iran), in the Indus Basin, eastern India and region, northwestern China, and surrounding the North China Plain. As many of these drying trends are attributed to human activity, the coexistence of high water shortage and drying trends are largely not coincidental and point to a global inability, so far, to manage sparse water resources for long term water security. Yet, just as regions of varied hazard levels differ in their sensitivity to water availability trends, populations of varied adaptive capacities differ in their vulnerability to similar combinations of hazard levels and water availability trends.

We thus conduct a global vulnerability analysis that incorporates all discussed considerations: hazard levels of water shortage and flooding, water availability trends, and adaptive capacity. Our definition of vulnerability derives from Turner et al. ${ }^{53}$ as the likelihood of a region to 'experience harm due to exposure to a hazard' and is operationalized here as the difference between a region's hazard level and its adaptive capacity. Similarly to other integrated global water assessments e.g. 14,33, we normalize our indicators to enable their direct comparison. Our scale of analysis is modified food production units (mFPU, $n=548$ ), which have been used in previous global water scarcity assessments ${ }^{26,27}$ and whose regional scale (median area $\approx 135,000$ $\mathrm{km}^{2}$ ) is interpreted to be commensurate with the effective resolution of GRACE observations $\left(\sim 150,000 \mathrm{~km}^{2}\right)^{54}$. We begin the assessment with mFPU estimates of water shortage and flooding occurrence and normalize each basin's estimate to a hazard level score. Subsequently, we modify each mFPU's hazard level based on the ratio of the mean water availability trend to the preexisting long-term mean annual precipitation per mFPU (1972-2001 period, see Methods for details). We justify the combination of water storage trends with water shortage and flooding indicators based on the intrinsic connectivity of groundwater and surface water resources, and the ability of soil moisture to drive significant changes in blue water demand and to alter flash flood generation. We refer to the modified water shortage hazard as water scarcity to reflect this combination of fluxes with storage trends. While GRACE TWS trends have been used to assess the predisposition of river basins to flooding ${ }^{55,56}$ and water security in the context of groundwater depletion during drought ${ }^{57}$ using more nuanced methods, we opt for a simple approach to enable a straightforward global application of the water availability trends in the parallel contexts of water scarcity and flooding. This approach offers first-order vulnerability estimates and avoids the methodological challenges of downscaling GRACE trends for physical modelling at local scales in this global analysis.

Vulnerability to flooding (and water scarcity) is derived from the difference between the modified flooding (and water scarcity) hazard levels and local adaptive capacity (Fig. 5a,b). We summarize results at the national scale and find Bangladesh, Myanmar, Ethiopia, and the Philippines to emerge among the most vulnerable nations to flooding, and Yemen, Syria, Eritrea, Pakistan, and Egypt to emerge among the most vulnerable nations to water scarcity. Comparing national water scarcity and flooding vulnerabilities enables a combined assessment of quantitative water resources vulnerability (Fig. 5c) and yields a global perspective of the most vulnerable nations amid recent hydrologic change. Through this process we can identify nations that are predominantly vulnerable to flooding (e.g. Philippines, Myanmar), predominantly vulnerable to water scarcity (e.g. Libya, Egypt, Iran, Syria), or are burdened by high vulnerability to both water scarcity and flooding (e.g. Somalia, Bangladesh, Ethiopia, Afghanistan, Haiti). Assessing the regional distribution of these vulnerabilities (Supplementary Fig. 3) shows South Asia and SubSaharan Africa, followed by Pacific and Central Asia, to be most vulnerable to flooding and the 
Middle East, Northern Africa, South Asia, and Sub-Saharan Africa to be most vulnerable to water scarcity. That South Asia and Sub-Saharan Africa emerge in both analyses as highly vulnerable reinforces the standing of these two regions as the veritable global epicenters of water insecurity. Conversely, the developed regions of the word (i.e. North America, Western Europe, and wealthy pacific nations Australia, New Zealand, and Japan) consistently rank among the least vulnerable to both hazards. These regions' low vulnerability scores, despite occasionally possessing moderate hazard levels, largely derive from high adaptive capacities and reinforce a prior observation that adaptive capacity is generally displaced from regions most in need. As social-ecological systems possess complicated properties such as non-linear feedback mechanisms ${ }^{15}$ (e.g. environmental thresholds and human agency), moderate hazard levels coinciding with moderate adaptive capacities become challenging to interpret. Thus, this analysis is particularly useful in identifying the extremes of the vulnerability spectrum (i.e. regions with disparate hazard levels and adaptive capacities), and we thereby limit our discussion of these results to nations and regions that satisfy this criteria.

This parallel analysis of flooding and water scarcity hazards is a more nuanced approach to consider these divergent phenomena in comparison to existing studies which conflate all hazards and social criteria into a single security metric. Yet, in spite of this fundamental difference, there is spatial agreement between this analysis and another recent existing global water security assessment (performed by Gain et al. ${ }^{34}$ ) if we interpret our definition of vulnerability to be compatible with Gain et al.'s definition of 'low' security (Supplementary Fig. 4). Both assessments identify South Asia (particularly Afghanistan, northern India, and Bangladesh) and northern SubSaharan Africa as the least water secure. Further, both assessments have similar low-to-high security distributions across the Americas, Europe, and Pacific Asia. While Gain et al. consider several additional criteria excluded from this assessment, such as water quality, sanitation access, and drought, the multiple criteria are arbitrarily weighted and combined (e.g. flooding frequency comprises $10 \%$ of the overall index score). However, since our vulnerability assessments, that consider the recent trends observed in freshwater availability, largely identify regions that correspond with Gain et al.'s analysis reinforces the notion that trends in freshwater resources are exacerbating the current water insecurities of the world.

In sum, we leverage the qualities of globally observed trends in freshwater availability to assess the social-ecological dimensions of changing water availability and the water security concerns of water scarcity and flooding. While the on-going GRACE Follow-On mission will provide clarity regarding the persistence or dissipation of the water availability trends observed during the original GRACE mission, this analysis provides an explicit social-ecological systems context to the previous decade and a half of observed terrestrial freshwater storage trends and gives systematic and evidential basis to many existing perceptions of global water security. 


\section{Figures:}
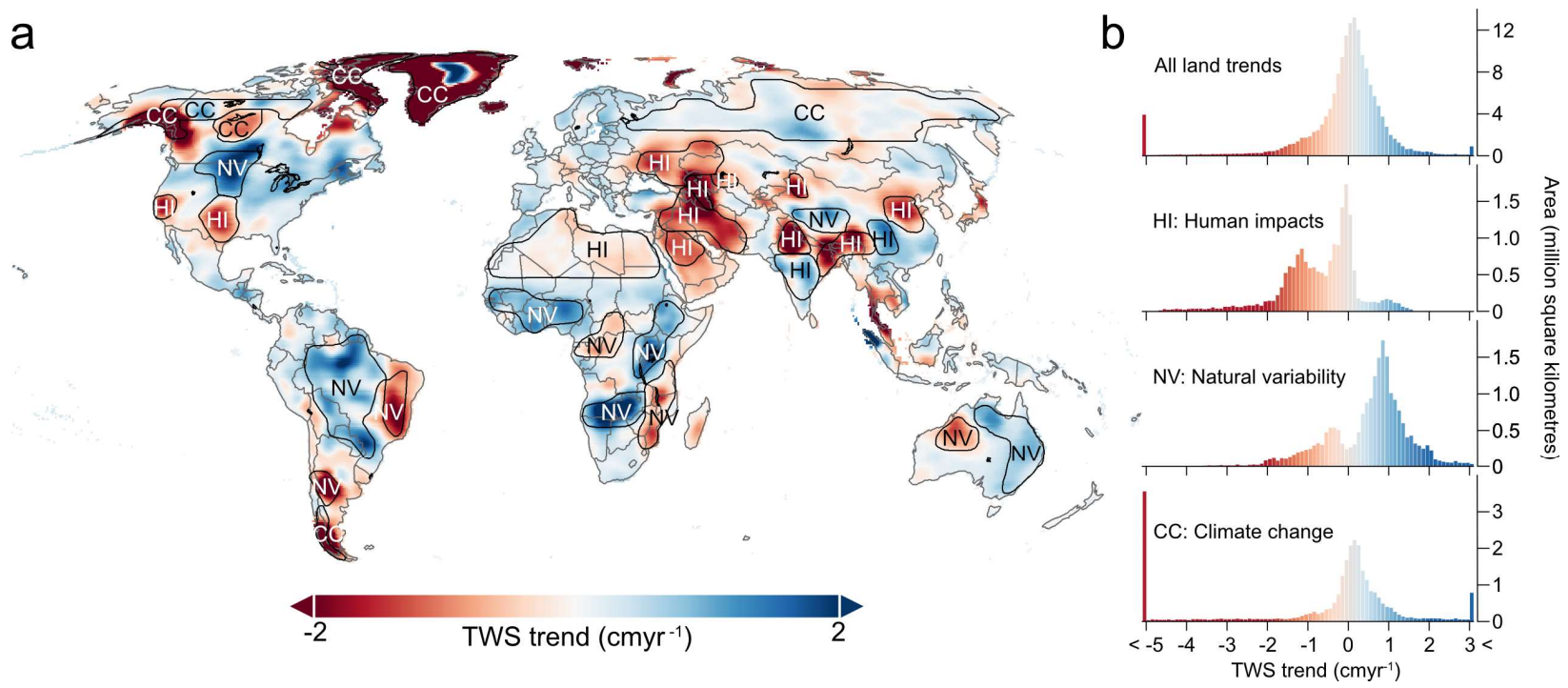

323 Fig. 1. Global freshwater availability trends observed by the GRACE satellite mission over the April 2002 - March 2016 period. (a) Map of the global water availability trends synthesized by Rodell et al. ${ }^{1}$, presented as annual rates with units of $\mathrm{cmyr}^{-1}$. Labels indicate attributed drivers of each trend, as identified in Rodell et al. ${ }^{1}$. NV represents natural variability, HI represents human impact, and CC represents climate change. (b) TWS trend distributions for the global land trends and each individual driver. Note the change in y-axis scale between plots. Trends for Antarctica, not shown on the map but attributed to climate change, are included in the distribution plots. 

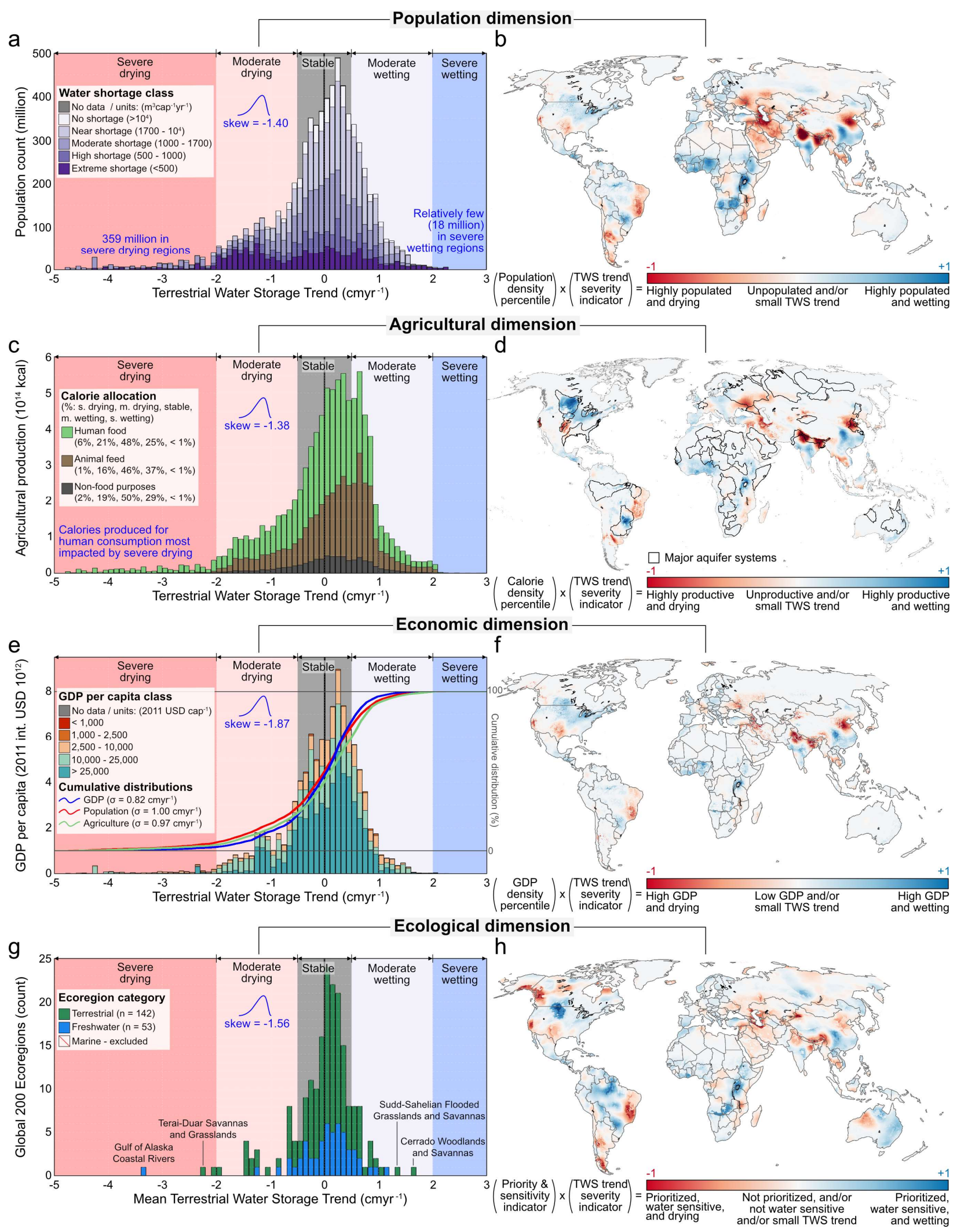

Fig. 2. The developing relationships between core social-ecological system dimensions and water availability. The population dimension: (a) The human population distribution relative to the water availability trends, with bar colors representing the water shortage class distribution. (b) Regions 
333 with high population density and strong wetting or drying trends. The agricultural dimension: (c) 334 Global crop production, measured in calories, relative to water availability trends with bar colors 335 representing the allocation distribution to food, feed, or nonfood uses. (d) Regions with high 336 calorie production density and strong wetting or drying trends. The economic dimension: (e) The 337 global GDP distribution, measured in 2011 international US dollars, relative to water availability 338 trends with bar colors representing the GDP per capita class distribution. The histogram is overlaid 339 with cumulative density functions of GDP, calorie production, and the human population, 340 evaluated in the direction of drying to wetting trends. (f) Regions with high GDP density and 341 strong wetting or drying trends. The ecological dimension: (g) The Global 200 terrestrial and 342 freshwater ecoregions based on their mean water availability trend. (h) Regions of ecological 343 prioritization, ecological water sensitivity, and strong wetting or drying trends. 
a

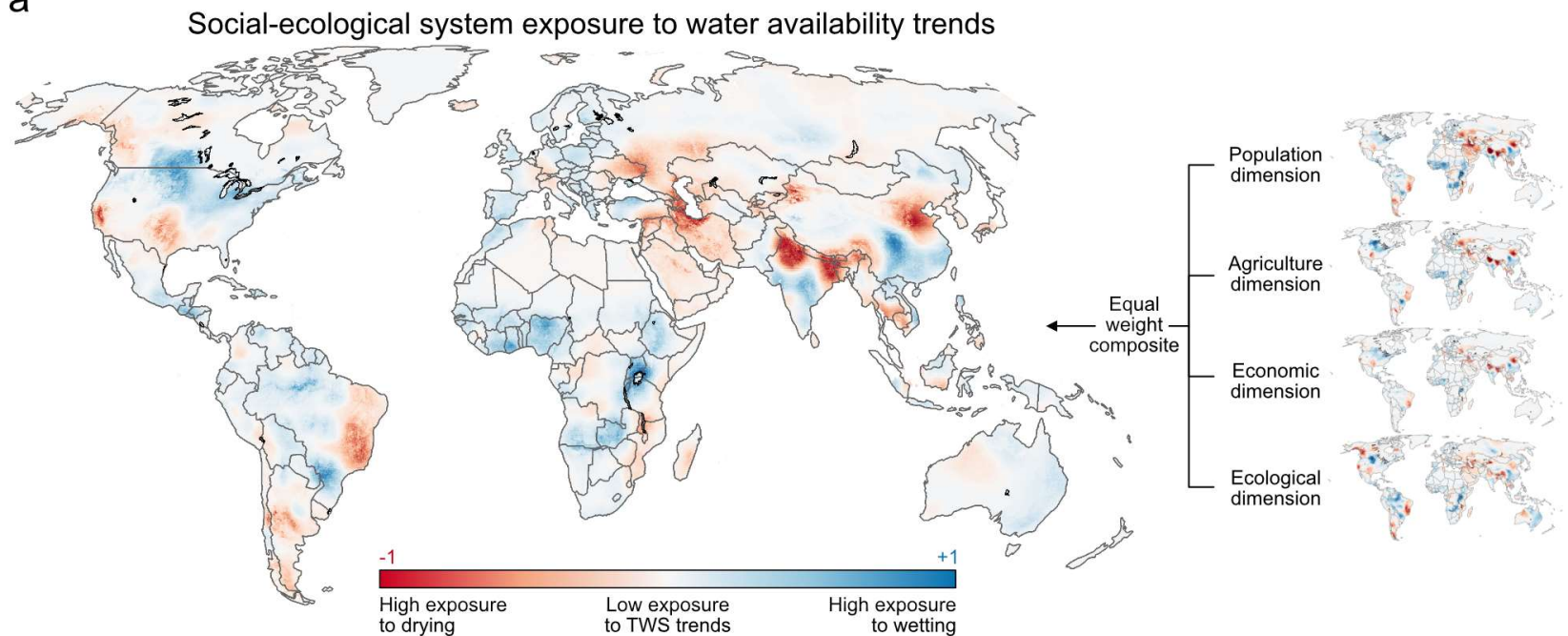

b

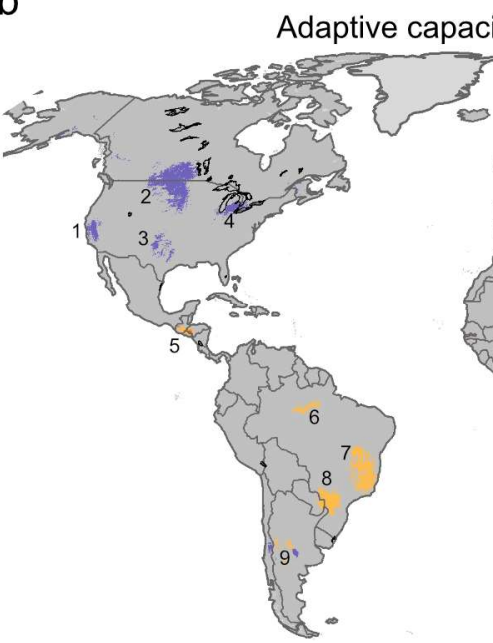

acity of highly exposed populations

Fig. 3. Water availability trend pressures on the collective social-ecological system. (a) Map displaying the combined exposure of all social-ecological system dimensions analyzed in Figure 2 , combined using an equal weight composite approach. (b) Map identifying the $5 \%$ most exposed areas to high social-ecological system pressures from the water availability trends and their adaptive capacity. Adaptive capacity is classified as high, moderate, or low using the global population's $80^{\text {th }}$ and $20^{\text {th }}$ adaptive capacity percentiles as thresholds. 

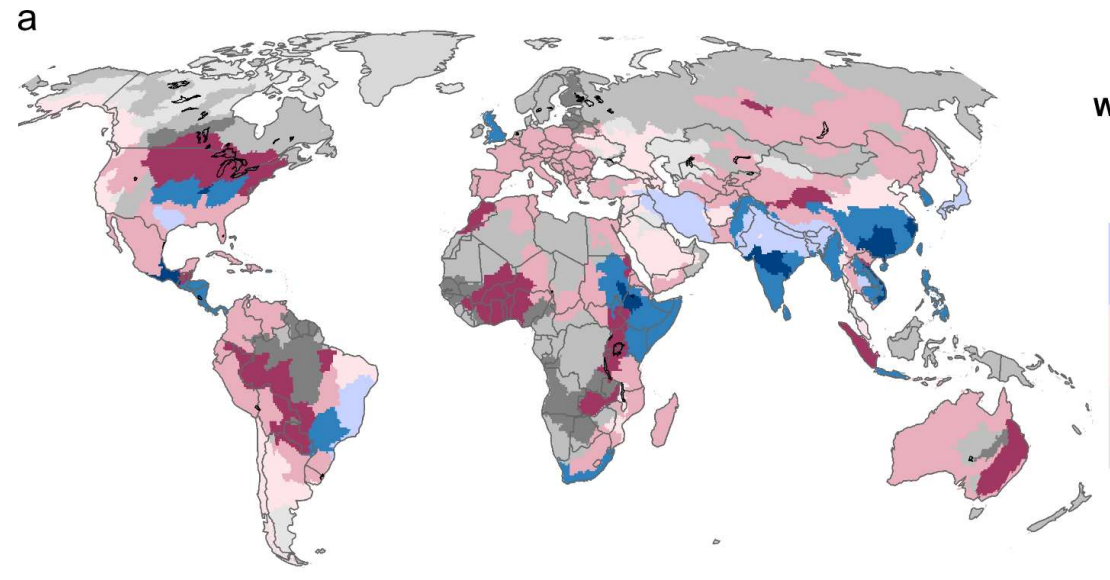

Water availability trend

b
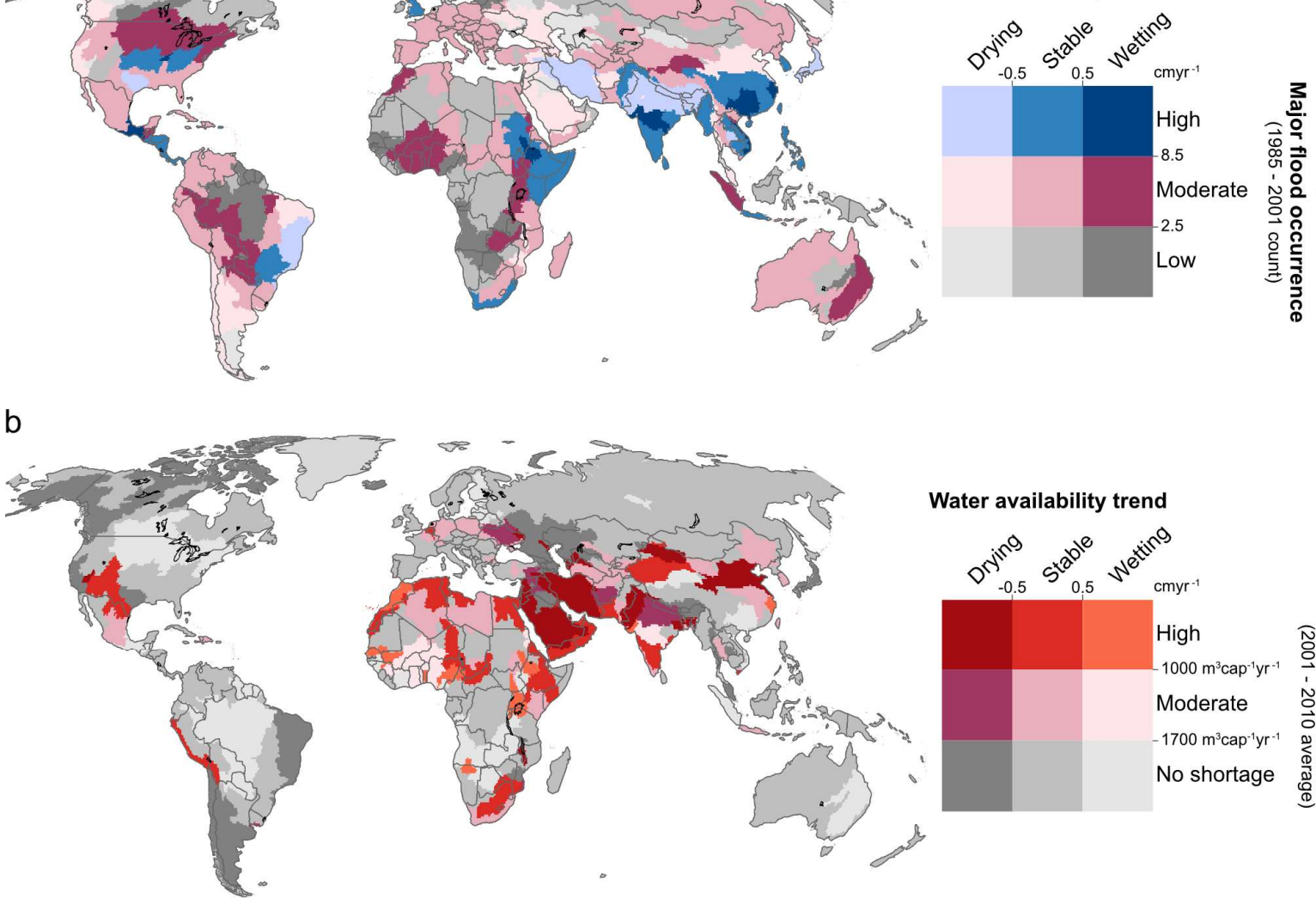

Fig. 4. Contextualizing the water availability trends with (a) flooding and (b) water shortage hazards. Hazard categories are assessed near the onset of the GRACE observations, and water availability trends are simplified to categories of drying, stable, and wetting. 
a

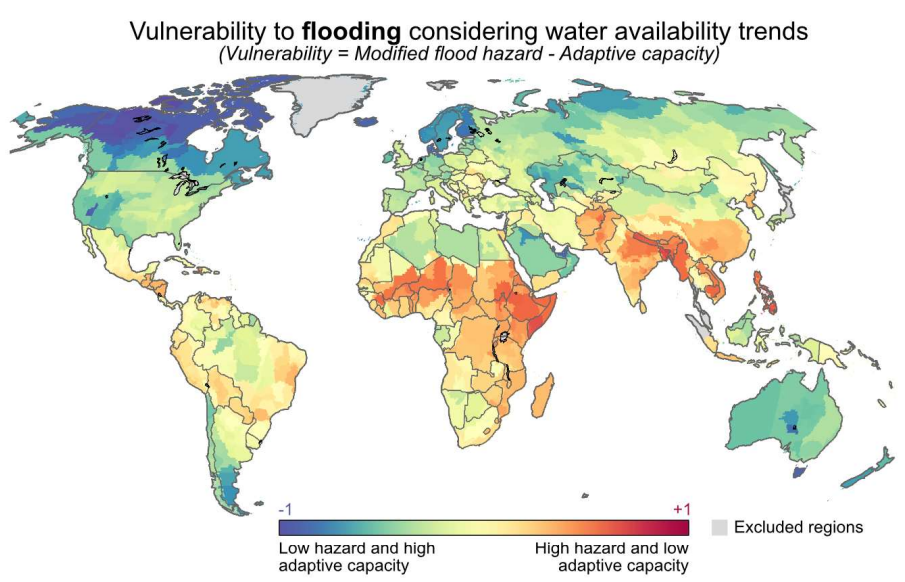

b

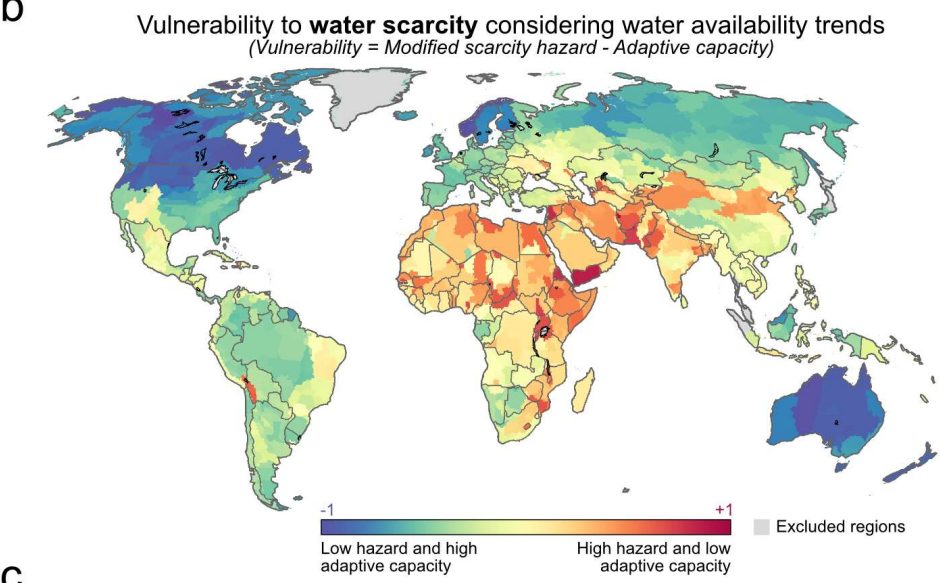

C

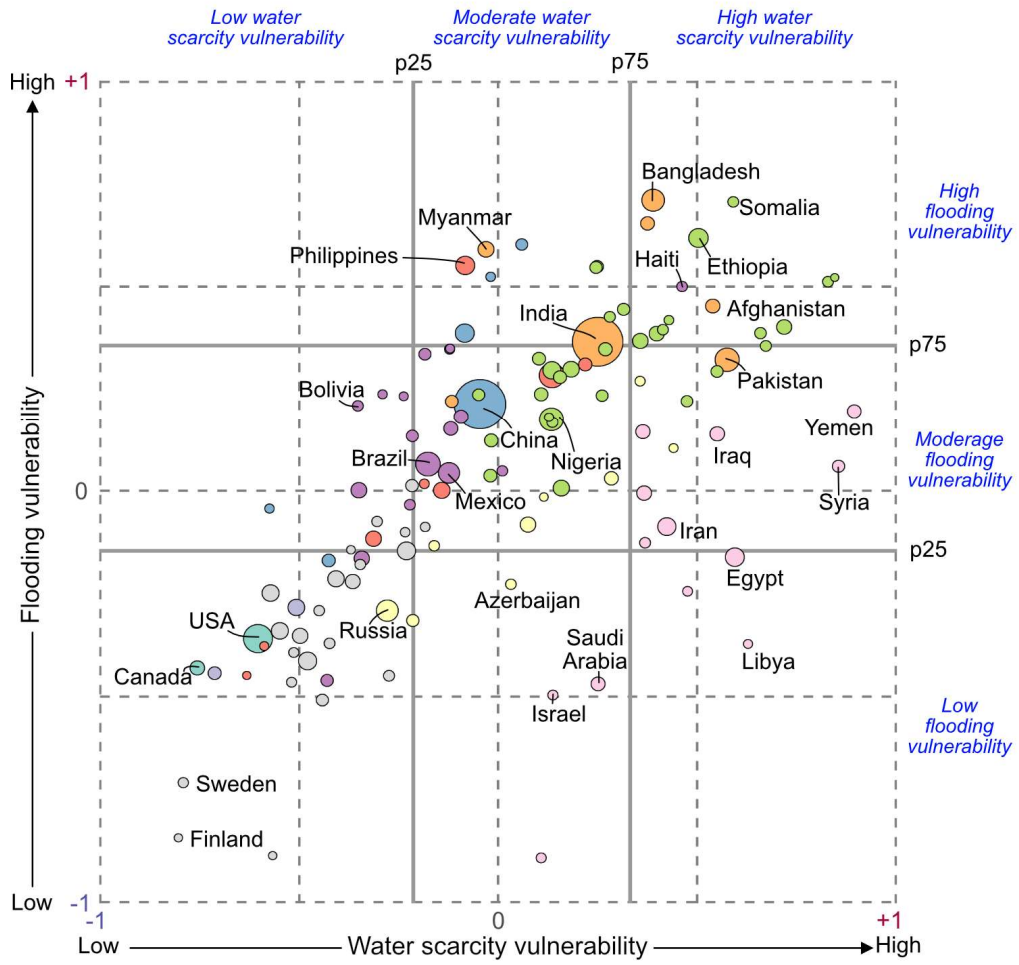

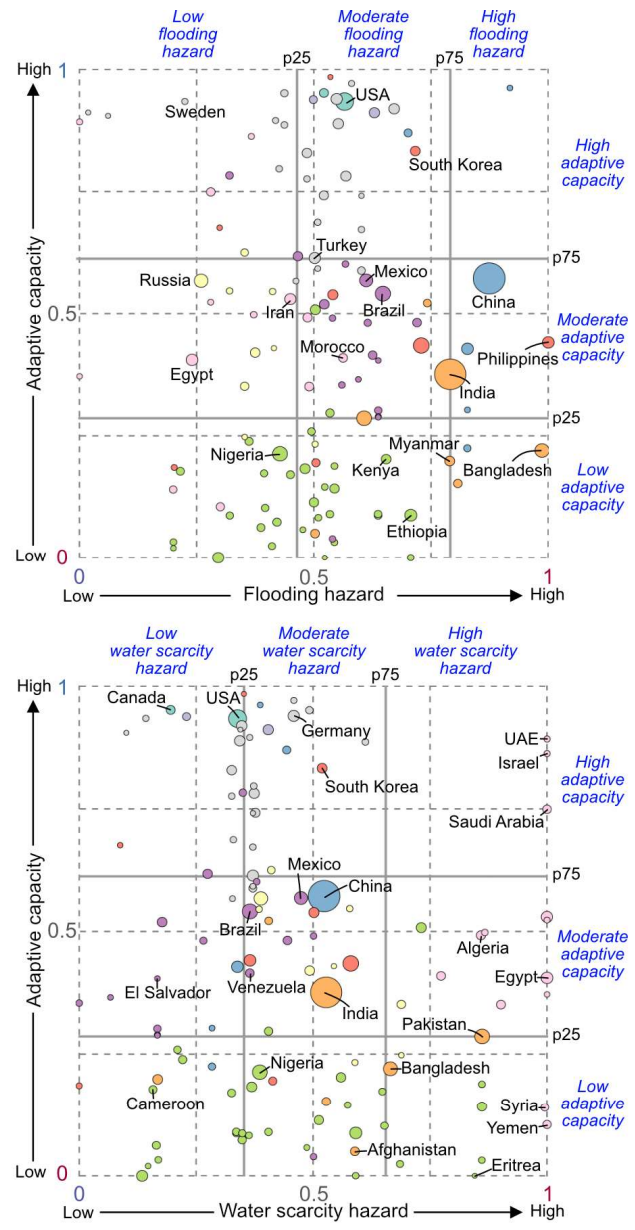

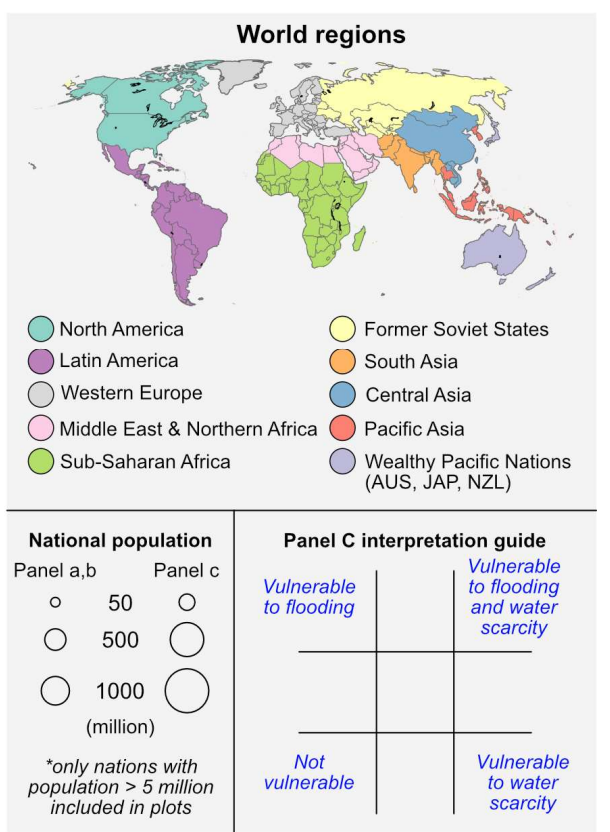


355 Fig. 5. Global (a) flooding and (b) water scarcity vulnerability assessments considering the water 356 availability trends. (c) Comparing national vulnerabilities to flooding and water scarcity. In all 357 graphs, nations are plotted according to their population-weighted median value, have their area 358 scaled based on population, and are colored to indicate the world region they belong to. Solid grey 359 lines labelled p25 and p75 represent the $25^{\text {th }}$ and $75^{\text {th }}$ global population-weighted percentiles of 360 each axis parameter. 


\section{Methods:}

Table of Contents:

M-1. Spatial resolution of analysis

M-2. Social-ecological dimensions

M-3. Water scarcity and flooding vulnerability analysis

M-4. Data sources

M-5. Code availability

\section{M-1. Spatial resolution of analysis}

All analysis is performed at a resolution of $0.05^{\circ}(\sim 5 \mathrm{~km}$ at the equator). The resolution was selected to reconcile the differences in input data resolution, which ranged from $0.5^{\circ}(\sim 50 \mathrm{~km})$ to $0.0083^{\circ}(\sim 1 \mathrm{~km})$. While scaling all data to the coarsest resolution would have simplified computational processing, aggregation has a moderating effect on intensive spatial properties (e.g. cropland density) which we sought to avoid. For extensive data (e.g. population count), raster resampling was performed to preserve the global sum of each distribution, while bilinear interpolation was performed for intensive data. When raster resampling was needed yet the raw resolution was a non-integer multiple or fraction of the operating resolution, aggregation was performed to the lowest common aggregation scale of both resolutions and then the data were resampled to the operating resolution. When data were provided in vector format, input data were rasterized using a constant value per vector feature. By converting all input data to raster format and presenting results as distributions rather than singular values where possible, we sought to minimize the modifiable areal unit problem ${ }^{58}$. A summary of the resolution homogenization process is provided below.

Summary of resampling processes to homogenize all data to $0.05^{\circ}$ resolution

\begin{tabular}{|c|c|c|}
\hline Dataset (see Data sources) & Raw resolution & Resampling process to $0.05^{\circ}$ \\
\hline TWS trends & $0.5^{\circ}+$ & $\begin{array}{c}\text { - Resample to } 0.05^{\circ} \text { (nearest neighbour) } \\
\text { Despite being a continuous dataset, nearest } \\
\text { neighbour resampling was selected to preserve } \\
\text { raw input values }\end{array}$ \\
\hline Population & $0.0083^{\circ}$ & - Aggregation (factor $=6$, sum) to $0.05^{\circ}$ \\
\hline $\begin{array}{l}\text { Crop calories } \\
\text { (Food, Feed, } \\
\text { Non-food) }\end{array}$ & $0.0833^{\circ}$ & $\begin{array}{l}\text { - Aggregation (factor }=3, \text { sum) to } 0.25^{\circ} \\
\text { - Resample to } 0.05^{\circ} \text { (nearest neighbour) } \\
\text { - Divide all cell values by } 25 \text { to preserve sum }\end{array}$ \\
\hline Cropland density & $0.0833^{\circ}$ & - Bilinear interpolate to $0.05^{\circ}$ \\
\hline Irrigation density & $0.0833^{\circ}$ & - Bilinear interpolate to $0.05^{\circ}$ \\
\hline Irrigation source & $0.0833^{\circ}$ & - Bilinear interpolate to $0.05^{\circ}$ \\
\hline GDP & $0.0083^{\circ}$ & - Aggregation (factor $=6$, sum) to $0.05^{\circ}$ \\
\hline GDP per capita & $0.0833^{\circ}$ & - Bilinear interpolate to $0.05^{\circ}$ \\
\hline Global 200 ecoregions & Vector & - Rasterized to $0.05^{\circ}$ \\
\hline $\begin{array}{l}\text { Groundwater head decline } \\
\text { to environmental flow } \\
\text { limits }\end{array}$ & $0.0833^{\circ}$ & - Bilinear interpolate to $0.05^{\circ}$ \\
\hline $\begin{array}{l}\text { Vegetation sensitivity to } \\
\text { water availability }\end{array}$ & $0.05^{\circ}$ & - None required \\
\hline
\end{tabular}




\begin{tabular}{|l|l|l|}
\hline Water shortage & $\begin{array}{l}\text { Vector } \\
\text { delineated at } \\
0.5^{\circ}\end{array}$ & $\begin{array}{l}\text { - Rasterize to grid at native } 0.5^{\circ} \\
\text { - Resample to } 0.05^{\circ} \text { (nearest neighbour) }\end{array}$ \\
\hline Flooding occurrence & Vector & - Rasterized to $0.05^{\circ}$ (count function) \\
\hline Adaptive capacity & $0.0833^{\circ}$ & - Bilinear interpolate to $0.05^{\circ}$ \\
\hline
\end{tabular}

382

383

† While the native resolution of GRACE observations is $\sim 3^{\circ}$, the Rodell et al. ${ }^{1}$ source data TWS trends are provided at $0.5^{\circ}$.

\section{M-2. Social-ecological dimensions}

\section{Distribution analysis}

For each of the population, agricultural, economic, and ecology dimensions, histograms (with a bin size of $0.1 \mathrm{cmyr}^{-1}$ ) summarize the distribution of each dimension's parameter against the water availability trends. For the population dimension, the global population is summarized against the water availability trends and is categorized by classes of water shortage. For the agricultural dimension, global calorie production is summarized and is categorized by allocation to food, feed, and nonfood uses. For the economic dimension, global GDP at PPP (2011 int. USD) is summarized and is categorized into classes of GDP per capita. The economic dimension also includes the cumulative distributions of the population (population count), agricultural (calories), and economic (GDP at PPP) dimensions. These are calculated by cumulatively summing each distribution across the water availability trend spectrum, at $0.1 \mathrm{cmyr}^{-1}$ increments, and normalizing by the global sum. For the ecological dimension, the mean water availability trend per Global 200 ecoregion is summarized and is categorized by terrestrial or freshwater classification. Marine ecoregions are excluded from the analysis as we focus on terrestrial water storage trends.

In the supplementary information, various distributions (TWS trends, irrigation water source, calorie yield, human food calories as a percentage of total food calories) are plotted against the axes of cropland density and irrigation density (Supplementary Fig. 1). Irrigation density is derived by multiplying the Global Map of Irrigation Areas' 'area equipped for irrigation' dataset by the 'area actually irrigated as a percentage of area equipped for irrigation' dataset. As the Global Map of Irrigation Areas' datasets are produced at differing scales and methods from the cropland density dataset, there are instances of irrigation density greater than cropland density. To reconcile this difference, we use cropland density as an upper maximum, and set all irrigation densities greater than local cropland densities to the cropland density. The reported values in Supplementary Fig. 1 are derived by binning cropland density and irrigation density at 5\% increments, and evaluating the area-weighted median value per combination of cropland and irrigation density bins.

\section{Mapping}

Each social-ecological dimension analyzed is summarized with a global map highlighting areas of significance per dimension that are experiencing strong water availability trends. For the population, agricultural, and economic dimensions, the maps are produced through two steps: deriving an area-weighted density percentile raster and multiplying this raster by a water availability trend severity raster. The percentile rasters are calculated by dividing each dimension's magnitude within each cell (e.g. population count, calorie production, GDP at PPP) by the cell area (approximated at the cell center using the WGS84 reference ellipsoid). This global density distribution is then normalized to a percentile distribution based on the global area-weighted 
percentiles of each dimension. For example, a grid cell that contains a population density that corresponds to the $75^{\text {th }}$ percentile the global area-weighted population density distribution is assigned a value of 0.75 . The water availability trend significance raster is derived by dividing the water availability trend raster by 2 , and clipping all results to the range $[-1,1]$. Effectively, this process assigns all TWS trends $\leq-2 \mathrm{cmyr}^{-1}$ a value of -1 , all TWS trends $\geq 2 \mathrm{cmyr}^{-1}$ a value of +1 , and assigns values based on linear interpolation within these limits. Multiplying the two derived rasters yields a product raster with values $[-1,1]$, where cells with values near -1 represent areas with a high dimension density (i.e. population, kilocalorie, or GDP) and strong drying trends, cells with values near +1 represent areas with a high dimension density and strong wetting trends, and values near 0 are produced from either (or both) low dimension density or small water availability trends.

For the ecological dimension, an extensive global distribution (such as the human population) is not readily available and alternatives (such as global species richness datasets) would require a substantial separate research effort (e.g. appropriately combining species richness datasets of amphibians, mammals, fish, etc.) to produce a similarly useful singular dataset. Instead, the associated map for the ecological dimension is the product of a derived indicator representing ecological priority and ecological water sensitivity and the water availability trend severity raster. The indicator combines the Global 200 list of priority ecoregions ${ }^{48}$, a vegetation sensitivity to water availability anomalies dataset ${ }^{49}$, and an environmental flow sensitivity to groundwater head decline dataset ${ }^{50}$ (see M-4 Data sources for descriptions). Of the 238 ecoregions, we use the 195 terrestrial and freshwater ecoregions and exclude the 43 marine ecoregions, as our analysis centers around terrestrial water storage trends. The vegetation sensitivity to water availability dataset is a sub-dataset in Seddon et al. ${ }^{49}$ 's Vegetation Sensitivity Index and is used here to approximate ecological sensitivity to soil moisture availability. The environmental flow sensitivity to groundwater head decline dataset comes from de Graaf et al. ${ }^{50}$ 's analysis of estimated head declines at which environmental flow needs are transgressed over the simulation period 19602100 and is used here to approximate ecological sensitivity to groundwater availability. Rather than implement the absolute magnitude of these critical estimated heads, we normalize the global results to a continuous scale to represent sensitivity, where smaller critical head declines correspond with high sensitivity scores. When creating the ecological dimension indicator, we equally weight ecological priority (represented by Global 200 ecoregions) and ecological water sensitivity (produced by equally weighting soil moisture sensitivity and groundwater head decline sensitivity). This derivation process is shown in Supplementary Figure 5. This normalized indicator, when multiplied by the water availability trend severity raster (similarly to the other dimension maps), produces the associated ecological dimension map. The produced raster ranges $[-1,1]$, where values near -1 indicate ecological priority, ecological water sensitivity, and drying conditions, values near +1 indicate ecological priority, ecological water sensitivity, and wetting conditions, and values near 0 can arise from a lack of ecological prioritization and water insensitivity, or small water availability trends.

The social-ecological system exposure to water availability trends map (Fig. 3a) is produced by equally weighting all dimension maps (population, agriculture, economic, ecology) into a single composite map. In this combined analysis, cell values near -1 indicate high population density, high calorie production density, high GDP density, ecological prioritization, high water sensitivity and drying conditions, values near +1 indicate similar properties with wetting conditions, and values near 0 indicate regions with overall low social-ecological system activity and/or small water availability trends. The subsequent map of highly exposed populations and their 
categorized adaptive capacities is developed by evaluating the $95^{\text {th }}$ area-weighted (excluding Greenland and Antarctica) percentile of absolute social-ecological system exposure to water availability trends (i.e. the absolute values in Fig. 3a) and the $80^{\text {th }}$ and $20^{\text {th }}$ population-weighted percentiles of adaptive capacity. We categorize the adaptive capacity dataset using populationweighted percentiles to reflect the exclusively social data inputs of the dataset. All areas with exposures greater than the $95^{\text {th }}$ area-percentile are classified as highly exposed, while adaptive capacities greater than the $80^{\text {th }}$ percentile, between the $80^{\text {th }}$ percentile and $20^{\text {th }}$ percentile, and below the $20^{\text {th }}$ percentile are classified as high, moderate, and low, respectively.

\section{M-3. Water scarcity and flooding vulnerability analysis}

To address the limitation that GRACE-observed TWS trends are presented without the context of existing quantitative water resource hazards, we evaluate the TWS trends dataset against datasets of flooding and water shortage. We select these hazards to address concerns that may arise from wetting and drying trends, although global water security analyses often primarily focus on water scarcity concerns. We utilize Kummu et al. ${ }^{27}$ 's decadal assessment of water shortage over the 2001-2010 time span. While Kummu et al. provide water shortage assessments for every decade from 1900-2010, as water shortage (or water crowding) is the ratio of water availability per capita per year, we select the most recent available decade to better reflect the growing global population despite its considerable overlap with the GRACE observation period. The shortage assessments are calculated at modified Food Production Units (mFPU), coincident with the study's underlying hydrological and water use models, and number 548 in total. The reference flooding occurrence dataset was derived from the Global Active Archive of Large Flood Events ${ }^{59}$, which is the most comprehensive and spatially explicit archive of flooding events from 1985 until present. We utilize the archive's flooding records from 1985-2001 so to exclude flood events that occurred during the GRACE observation period and separate pre-existing hazard levels from the observed trends. For spatial consistency within this analysis, we summarize flooding occurrence within each modified Food Production Unit using the maximum flood count per $0.05^{\circ}$ grid cell over $1985-2001$ within each mFPU.

To produce easily interpretable outcomes, we simplify the water availability trends into categories of drying $\left(\leq-0.5 \mathrm{cmyr}^{-1}\right)$, stable, and wetting $\left(\geq 0.5 \mathrm{cmyr}^{-1}\right)$. As we apply the water shortage and flooding hazards at the mFPU scale, we aggregate the gridded water availability trends to the mFPU scale by evaluating the area-weighted mean TWS trend per mFPU. We choose the magnitude of $0.5 \mathrm{cmyr}^{-1}$ to identify drying and wetting trends as these magnitudes are well beyond mean estimated GRACE TWS trend uncertainty ranges, and thus indicate clear wetting and drying trends (see GRACE TWS trend uncertainty discussion in M-4. Data sources). In Figure 4, we simply map the relationship between water shortage and flooding hazard levels with the water availability trend classes.

We conduct our vulnerability analysis based on Turner et al. ${ }^{53}$ 's definition of vulnerability and Varis et al. ${ }^{14}$ 's derivation of adaptive capacity. Bringing these concepts together, we operationalize the vulnerability to flooding and water shortage hazards in the context of the observed water availability trends through equation 1.

$$
V\left(H_{i, j}\right)=H_{\text {norm }}\left(C\left(r_{i}\right)+M\left(\overline{\frac{T W S t_{j}}{L T M A P_{j}}}\right)_{i}\right)-A C_{j}
$$


where $V$ represents the vulnerability of mFPU $i$ at grid cell $j$ to the hazard, $H$, based on its categorized score, $C\left(r_{i}\right)$, modified by a function, $M$, of the $i$ averaged ratio of water availability trend to long-term mean annual precipitation $(\overline{T W S t / L T M A P})$, normalized to the scale $0-1\left(H_{\text {norm }}\right)$ and subtracted by the already normalized adaptive capacity, $A C$, at grid cell $j$.

The reference levels of water shortage are based on Falkenmark ${ }^{28}$ 's original water stress level code, while the reference levels of flooding occurrence are generally based on existing categorial flooding hazard assessment tools (e.g. the World Resources Institute's Aqueduct Water Risk Atlas [https://www.wri.org/applications/aqueduct/water-risk-atlas/], or the World Wildlife Foundation's Water Risk Filter [https://waterriskfilter.panda.org/]) that categorize flooding hazards based on flood occurrence counts. Following Falkenmark's original five levels of water stress, we categorize both reference hazards on a 0-5 scale $\left(C_{i}\right)$. See table below for classification system details.

\begin{tabular}{|c|c|c|}
\hline Categorized level $(\boldsymbol{C})$ & Flooding hazard $\left(\boldsymbol{r}_{\boldsymbol{i}}\right)$ & Water shortage data $\left(\boldsymbol{r}_{\boldsymbol{i}}\right)$ \\
\hline 5 (Highest) & 29 (Maximum global value) & $333 \mathrm{~m}^{3} \mathrm{cap}^{-1} \mathrm{yr}^{-1}$ or less \\
$\cdots$ & $\ldots$ & $\cdots$ \\
4 & 16 & $500 \mathrm{~m}^{3} \mathrm{cap}^{-1} \mathrm{yr}^{-1}$ \\
$\cdots$ & $\cdots$ & $\cdots$ \\
$\cdots$ & 8 & $1000 \mathrm{~m}^{3} \mathrm{cap}^{-1} \mathrm{yr}^{-1}$ \\
2 & $\cdots$ & $\cdots$ \\
$\cdots$ & 3 & $1700 \mathrm{~m}^{3} \mathrm{cap}^{-1} \mathrm{yr}^{-1}$ \\
$\cdots$ & $\cdots$ & $\cdots$ \\
0 (Lowest) & 1 & $10000 \mathrm{~m}^{3} \mathrm{cap}^{-1} \mathrm{yr}^{-1}$ \\
$\cdots$
\end{tabular}

Note that ( $\cdots$ ) indicates linear interpolation between values.

To simply incorporate the water availability trends into the vulnerability assessment, we modify each mFPU's reference level of water shortage and flooding hazards (i.e. $\left.C\left(r_{i}\right)\right)$ based on a function (i.e. $M$ ) of the mFPU's area-weighted mean ratio of water availability trends to longterm mean annual precipitation (i.e. $\overline{T W S t / L T M A P}$ ). We normalize water availability trends by the long-term mean annual precipitation to indicate the significance of the trends in relation to the primary hydrologic input of the terrestrial water cycle. To determine the long-term mean annual precipitation of each mFPU, we implement the Global Precipitation Climatology Centre (GPCC), Climate Research Unit Timeseries (CRU TS), and the University of Delaware (UDEL) global monthly precipitation datasets over the 30-year period preceding the GRACE mission (19722001). The derived 1972-2001 mean annual precipitation datasets of the GPCC, CRU, and UDEL products that are averaged to produce the long-term mean annual precipitation dataset and are shown in Supplementary Figure 6.

The ratios of water availability trends to long-term mean annual precipitation better reflect the significance of the water availability trends relative to the local hydrological system than the trend magnitudes alone (e.g. $1 \mathrm{cmyr}^{-1}$ of wetting in an arid climate is more significant than $1 \mathrm{cmyr}^{-}$ ${ }^{1}$ of wetting in a tropical climate). These results are subsequently slightly modified as all extreme values (i.e. ratios less than the $5^{\text {th }}$ percentile and greater than the $95^{\text {th }}$ percentile) are set to the $5^{\text {th }}$ and $95^{\text {th }}$ percentile values to diminish the effect of these extremes on the summary statistics. With this modification, the mFPU ratios of TWSt/LTMAP have a mean of $-0.50 \%$ and a standard deviation of $1.78 \%$ (Supplementary Fig. 7a). These mFPU averaged TWSt/LTMAP ratios are then 
used to modify the current mFPU hazard levels of water shortage and flooding through the process described below.

To derive the hazard level modification value per mFPU, we normalize the $\overline{T W S t / L T M A P}$ ratios by their standard deviation (Supplementary Fig 7b). This effectively produces a modified TWSt/LTMAP ratio Z-score per mFPU (modified as it does not center the Z-score about the mean, which was done to preserve drying and wetting trends having a modifying impact consistent with their trend direction). We set the maximum possible modifying effect to a full hazard category, corresponding to a $\overline{T W S t / L T M A P}$ ratio equal to or greater than two standard deviations, where wetting trends increase flooding hazards and decrease water scarcity hazards, and drying trends increase water scarcity hazards and decrease flooding hazards. This process of (1) scaling the mFPU mean TWSt/LTMAP ratios to their hazard modification values (where TWSt/LTMAP $\geq 2 \sigma$ are set to a maximum hazard level modification of 1.0), and (2) setting the modification direction (i.e. increasing or decreasing the hazard level) based on flooding of water scarcity analysis is represented by function $M$ in equation 1 . This simplified application enables the water availability trends to be considered in the dual contexts of water scarcity and flooding hazards in a way that emphasizes the possible modifying effect the trends impose on hazard levels while avoiding the methodological challenges of down-scaling GRACE TWS trends to local physical models.

This $\overline{T W S t / L T M A P}$ ratio derived water availability modifier is then added to the reference level of water shortage and flooding, individually. Where modifications would move hazard levels beyond the limits of the $0-5$ scale (e.g. water shortage hazard level of 0 with wetting trends), the modification effects are reduced to preserve the original 0-5 range as it is not meaningful to possess less than no water shortage, or to quantify increasing water shortage pressures for regions already beyond the water barrier. The table below provides some examples to assist in understanding the hazard level modification process, with corresponding equation 1 variables shaded in grey.

\begin{tabular}{|c|c|c|c|c|c|c|c|}
\hline \multicolumn{8}{|c|}{ Water shortage hazard modification examples } \\
\hline $\begin{array}{l}\text { Reference } \\
\text { water } \\
\text { shortage } \\
\left(\mathrm{m}^{3} \mathrm{cap}^{-1} \mathrm{yr}^{-1}\right)\end{array}$ & $\begin{array}{c}\text { Reference } \\
\text { hazard } \\
\text { level }\end{array}$ & $\begin{array}{l}\text { TWS } \\
\text { trend } \\
(\mathrm{cm} \\
\left.\mathrm{yr}^{-1}\right)\end{array}$ & $\begin{array}{l}\text { Long-term } \\
\text { mean annual } \\
\text { precipitation }\end{array}$ & $\begin{array}{l}\text { TWS } \\
\text { trend as } \\
\text { percent of } \\
\text { LTMAP }\end{array}$ & $\begin{array}{c}\text { TWS/LTMAP } \\
\text { divided by } \\
\text { standard } \\
\text { deviation } \\
(1.78 \%)\end{array}$ & $\begin{array}{c}\text { Hazard } \\
\text { level } \\
\text { modific- } \\
\text { ation }\end{array}$ & $\begin{array}{c}\text { Modified } \\
\text { hazard } \\
\text { level }\end{array}$ \\
\hline$r_{i}$ & $C\left(r_{i}\right)$ & $T W S t$ & LTMAP & $\overline{T W S t / L T M A P}$ & \multicolumn{2}{|c|}{$M(\overline{T W S t / L T M A P})$} & $C()+M()$ \\
\hline 450 & 4.30 & 0.85 & $1140 \mathrm{~mm}$ & $0.75 \%$ & 0.42 & -0.42 & 3.88 \\
\hline 900 & 3.20 & -1.07 & $450 \mathrm{~mm}$ & $-2.38 \%$ & -1.34 & 1.34 & 4.54 \\
\hline \multicolumn{8}{|c|}{ Flooding hazard modification examples } \\
\hline $\begin{array}{l}\text { Reference } \\
\text { flooding } \\
\text { occurrence } \\
\text { (count) }\end{array}$ & $\begin{array}{c}\text { Reference } \\
\text { hazard } \\
\text { level }\end{array}$ & $\begin{array}{l}\text { TWS } \\
\text { trend } \\
(\mathrm{cm} \\
\left.\mathrm{yr}^{-1}\right)\end{array}$ & $\begin{array}{l}\text { Long-term } \\
\text { mean annual } \\
\text { precipitation }\end{array}$ & $\begin{array}{l}\text { TWS } \\
\text { trend as } \\
\text { percent of } \\
\text { LTMAP }\end{array}$ & $\begin{array}{c}\text { TWS/LTMAP } \\
\text { divided by } \\
\text { standard } \\
\text { deviation } \\
(1.78 \%)\end{array}$ & $\begin{array}{l}\text { Hazard } \\
\text { level } \\
\text { modific- } \\
\text { ation }\end{array}$ & $\begin{array}{c}\text { Modified } \\
\text { hazard } \\
\text { level }\end{array}$ \\
\hline$r_{i}$ & $C\left(r_{i}\right)$ & $T W S t$ & LTMAP & $\overline{T W S t / L T M A P}$ & \multicolumn{2}{|c|}{$M(\overline{T W S t / L T M A P})$} & $C()+M()$ \\
\hline 1 & 1.00 & -0.85 & $450 \mathrm{~mm}$ & $-1.89 \%$ & -1.06 & -1.06 & 0 \\
\hline 10 & 3.25 & 1.07 & $1140 \mathrm{~mm}$ & $0.94 \%$ & 0.53 & 0.53 & 3.78 \\
\hline
\end{tabular}

After this hazard level modification process, the modified hazards are normalized to the scale $0-1\left(H_{\text {norm }}\right)$ by dividing by 5 and then are subtracted by the normalized adaptive capacity $(A C)$ to produce the vulnerability score. Vulnerability scores near +1 indicate high vulnerability 
(high hazard level and low adaptive capacity), while vulnerability scores near -1 indicate low vulnerability (low hazard level and high adaptive capacity). These final steps are demonstrated below, with corresponding equation 1 variables shaded in grey. We note a semantic shift from referring to water shortage hazards to water scarcity vulnerabilities so to reflect the combination of fluxes with storage trends.

\begin{tabular}{|c|c|c|c|}
\hline \multicolumn{4}{|c|}{ Water scarcity vulnerability examples } \\
\hline $\begin{array}{c}\text { Modified hazard level } \\
(0-5 \text { scale })\end{array}$ & $\begin{array}{c}\text { Normalized hazard } \\
\text { level }(0-1 \text { scale })\end{array}$ & $\begin{array}{c}\text { Adaptive capacity } \\
(0-1 \text { scale })\end{array}$ & Vulnerability score \\
\hline$C()+M()$ & $H_{\text {norm }}(C+M)$ & $A C$ & $V$ \\
\hline 3.88 & 0.78 & 0.82 & -0.04 \\
\hline 4.54 & 0.91 & 0.15 & 0.76 \\
\hline \multicolumn{4}{|c|}{ Flooding vulnerability examples } \\
\hline $\begin{array}{c}\text { Modified hazard level } \\
(0-5 \text { scale })\end{array}$ & $\begin{array}{c}\text { Normalized hazard } \\
\text { level }(0-1 \text { scale })\end{array}$ & $\begin{array}{c}\text { Adaptive capacity } \\
(0-1 \text { scale })\end{array}$ & Vulnerability score \\
\hline$C()+M()$ & $H_{\text {norm }}(C+M)$ & $A C$ & $V$ \\
\hline 0 & 0 & 0.24 & -0.24 \\
\hline 3.78 & 0.76 & 0.36 & 0.40 \\
\hline
\end{tabular}

The effect of this hazard level modification process on the vulnerability assessment outcomes are shown in Supplementary Figures 8 and 9.

\section{M-4. Data sources}

Here we identify our data sources and selection process. Our intention was to select the most recent, reputable, and globally available data requiring the least amount of manipulation during analysis. As best as possible, we attempt to align our data inputs for the year 2015 for temporal consistency near the end of the GRACE mission (2002-2016).

1. Water availability trends

2. Population

3. Water shortage

4. Flood occurrence

5. Cropland density

6. Crop production and allocation

7. Irrigated areas

8. GDP at PPP
9. GDP per capita

10. Ecological priority regions

11. Vegetation sensitivity index

12. Environmental flow sensitivity

13. Adaptive capacity

14. Precipitation

15. World regions

\section{Water availability trends}

\section{Data source: Rodell et al. ${ }^{1}$}

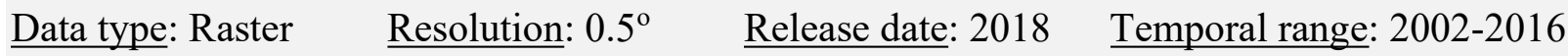

Description:

The dataset provides annual TWS trends obtained by linearly regressing 14-year TWS anomaly observations, which are referred to in ref. ${ }^{1}$ as 'apparent trends' in freshwater availability. As noted in the main text, TWS is the aggregate of groundwater, soil moisture, surface water, ice and snow storages. While the GRACE mission and the synthesis of its observations provide an unprecedented perspective of global water movement, four limitations of the dataset should be noted. First, the observation period is considerably shorter than the 30 -year maxim employed by 
climate analyses. Second, the reporting of the apparent trends as linear trends does not consider the implications of nonlinear change, interannual oscillations, nor the uncertainty they introduce. Third, while GRACE TWS anomaly measurement uncertainty is $2 \mathrm{~cm}$ e.g. 36 , no gridded global uncertainty analysis has been conducted for the TWS anomaly trends (discussion continued below). Fourth, earthquake interference accounts for the TWS trends reported for Sumatra and the Malay Peninsula (2004 Indian Ocean earthquake) and in Tohoku, Japan (2011 Tohoku earthquake). We thus exclude these regions from our analysis as they are not related to water storage trends. The extent of regions removed due to earthquake interference are shown in Supplementary Figure 10.

GRACE TWS trend uncertainties derive from three sources. The first source of uncertainty is variability between the three GRACE mass concentration block solutions (mascons): the Jet Propulsion Laboratory mascon (JPL-M), the Center for Space Research mascon (CSR-M), and the Goddard Space Flight Center mascon (GSFC-M). The second source of uncertainty is found in the uncertainty of each mascon solution's linear regression. The third source of uncertainty derives from glacial isostatic adjustment model error. However, while a gridded uncertainty assessment does not exist, both Rodell et al. ${ }^{1}$ and Scanlon et al. ${ }^{25}$ estimate the uncertainty of TWS anomaly trends at the region and basin scale, respectively. The regional TWS trend uncertainties presented by Rodell et al., which cover 34 distinct regional trends in GRACE TWS trends, range from 0.04 to $1.14 \mathrm{cmyr}^{-1}$ with an area-weighted mean uncertainty of $0.24 \mathrm{cmyr}^{-1}$ (Supplementary Table 4) when assuming a constant water density of $999.7 \mathrm{kgm}^{-3}$. Scanlon et al., conversely, evaluate GRACE TWS trends for 186 river basins and provide uncertainty estimates for a subset of 41 river basins in the supporting information. These basin uncertainties range from $0.013 \mathrm{cmyr}^{-1}$ to 0.5 $\mathrm{cmyr}^{-1}$, with an area-weighted mean uncertainty of $0.11 \mathrm{cmyr}^{-1}$ (Supplementary Table 5).

Justification:

The GRACE mission's TWS trend dataset is the first global observational dataset of terrestrial freshwater storage trends, currently exists without alternative, and serves as the central data source to this analysis.

\section{Population}

Data source: Gridded Population of the World (GPWv4) ${ }^{60}$

\section{Data type: Raster $\quad$ Resolution: $0.0083^{\circ}$ Release date: 2018 Temporal range: 2015}

Description:

The GPWv4 dataset provides gridded population count at 30 -second resolution $(\sim 1 \mathrm{~km}$ at the equator) for the years 2000, 2005, 2010, 2015, and 2020. Of the nine datasets made available through GPWv4, we utilize the United Nation's World Population Prospects (UN WPP) adjusted dataset for the year 2015, as it is consistent with national census data and United Nations country totals and is the GWPv4 recommended dataset for global analysis.

Justification:

While GWPv4 was selected instead of the Global Human Settlement Population Grid (GHS-POP), GHS-POP is a spatially distributed dataset of GWPv4 at finer scales. However, as the operating resolution of this analysis is coarser than the raw GWPv4 or GHS-POP data, the datasets become interchangeable once spatially aggregated to our operating resolution.

\section{Water shortage}

Data source: Kummu et al. ${ }^{27}$ 
Description:

The water shortage dataset is a product of Kummu et al.'s assessment of water shortage at decadal time steps from 1900-2010. The analysis is performed at the resolution of modified food production units, which were modified to be consistent with the underlying hydrological (WaterGAP2) and water use models used in the analysis. Water shortage is calculated using Falkenmark's water crowding index and has units of $\mathrm{m}^{3} \mathrm{cap}^{-1} \mathrm{yr}^{-1}$. Kummu et al. estimate water shortage using the 10-year annual average per modified food production unit. As the climate data used in the analysis is limited to the 1901-2001 period, the 2001-2010 water shortage estimates are based on 1991-2000 climate data but reflect the population growth of the 2001-2010 period.

639 Justification:

The water shortage analysis by Kummu et al. is the most recent and methodologically transparent global water shortage analysis to the authors' knowledge.

\section{Flooding occurrence}

643 Data source: Global Active Archive of Large Flood Events ${ }^{59}$

\section{Description:}

The Global Active Archive of Large Flood Events provides comprehensive data summarizing every reported large flood event since 1985, including shapefiles of affected areas of each flood, and has been incorporated in water decision tools (e.g. the Water Risk Atlas, the Water Risk Filter) and in Gain et al. ${ }^{34}$ to represent flood frequency. We limit our use of the flood archive to the 1985-2001 period to only consider events preceding the GRACE mission.

652 Justification:

653 We select the Dartmouth Flooding Observatory dataset due to its comprehensive nature and its typical use as the flooding frequency reference dataset in past global water assessments.

655

656

657

658

659

660

661

662

663

664

665

666

667

668

\section{Cropland density}

Data source: Ramankutty et al. ${ }^{61}$

Data type: Raster $\quad$ Resolution: $0.0833^{\circ}$ Release date: 2008 Temporal range: 2000

Description:

Global cropland area fraction evaluated at a resolution of 5-minutes.

Justification:

Alternative cropland extent data products exist, namely the Global Food Security AnalysisSupport Data at 30 Meters (GFSAD30) Project which mapped cropland extent at $30 \mathrm{~m}$ resolution for the year 2015. However, deriving cropland density at our operating resolution $\left(0.05^{\circ}\right)$ from a $30 \mathrm{~m}$ product was not pursued for computational reasons (aggregation factor $>180$ ), and as no preproduced alternative cropland density datasets were readily found, the Ramankutty et al. dataset was selected.

\section{Crop production and allocation}

\section{Data source: Cassidy et al. ${ }^{62}$}



Description:

671 Total calories produced for usage as food, feed, and non-food products, evaluated at a 672 resolution of 5-minutes.

673 Justification:

Cassidy et al.'s crop production and allocation to human food, animal feed, or nonfood uses dataset was selected for its temporal consistency with the Ramankutty et al. cropland density dataset, and as no alternatives exist to the authors' knowledge.

677

678

679

680

681

682

683

684

685

686

687

688

689

690

691

692

693

694

695

696

697

698

699

700

701

702

703

704

705

706

707

\section{Irrigated Areas}

Data source: Global Map of Irrigation Areas (GMIA) version $5^{63}$

Data type: Raster $\quad$ Resolution: $0.0833^{\circ}$ Release date: 2013 Temporal range: 2005

Description:

Global map of area equipped for irrigation as a percentage of each grid area. Additional GMIA layers include the area actually irrigated as a percentage of the area equipped for irrigation, and area irrigated with groundwater, surface water, and non-conventional sources as a percent of area equipped for irrigation.

Justification:

The GMIA is the most frequently used, spatially explicit data source of irrigated areas. An alternative dataset is found in the Global Food Security-support Analysis Data Crop Mask dataset, which offers a five class global cropland map. However, the GFSAD1KCM dataset doesn't provide density estimates nor irrigation water sources, which we find useful in the GMIA dataset.

\section{Gross domestic product (GDP) at purchasing power parity}

Data source: Kummu et al. ${ }^{64,65}$

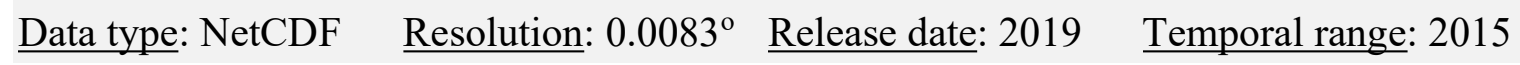

Description:

Gross domestic production (GDP) in 2011 international US dollars evaluated at 30-second resolution for years 1990, 2000, and 2015. We select the 2015 time step.

\section{Justification:}

The best alternative gridded GDP dataset is the UNEP/GRID Geneva gridded GDP at $\sim 1$ $\mathrm{km}$ resolution, however the methods the UNEP/GRID Geneva dataset provides are less transparent. Thus, we select the Kummu et al. dataset on this basis, and as it is the more recent of the two products.

\section{Gross domestic product (GDP) per capita}

Data source: Kummu et al. ${ }^{64,65}$

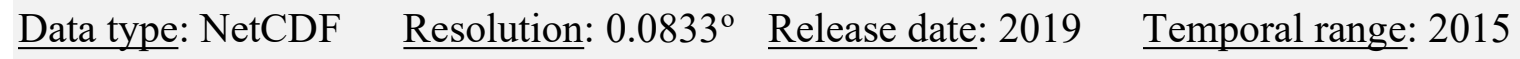

Description:

GDP per capita in 2011 international US dollars evaluated for administrative units for each of the years 1990-2015. We select the 2015 time step.

Justification: 
The Kummu et al. GDP per capita dataset was selected for its consistency with the GDP dataset used (also from Kummu et al.) and as it is the most recent and methodologically transparent global GDP per capita dataset.

\section{Priority ecological regions}

\section{Data source: Global 200: Priority Ecoregions for Global Conservation ${ }^{48}$}

\section{Data type: Vector Resolution: N/A Release date: 2002 Temporal range: N/A}

Description:

The Global 200 ecoregions are a delineated set of 238 areas with high biodiversity and ecosystem representativeness, based on the parameters of species richness, endemic species, higher taxa, unusual ecological or evolutionary phenomena, and habitat rarity ${ }^{48}$.

Justification:

The Global 200 list is one of several global biodiversity conservation initiatives. We select the Global 200 list instead of the Biodiversity Hotspots or the Ramsar Wetlands as we found the Global 200 to be less regionally-biased in its distribution and constructed on more holistic foundations in comparison to the existing alternatives.

\section{Vegetation sensitivity to water availability}

Data source: Seddon et al. ${ }^{49}$

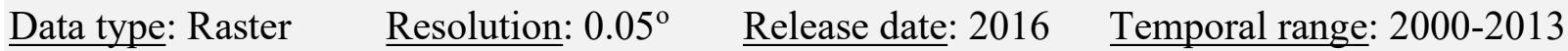

\section{Description:}

The vegetation sensitivity to water availability dataset comes from Seddon et al.'s vegetation sensitivity index (VSI). The VSI is produced by comparing the variance in the enhanced vegetation index (EVI) to time series data of three climate variables: air temperature, water availability, and cloud cover over the 2000-2013 period. The analysis uses the ratio of actual evapotranspiration to potential evapotranspiration (AET/PET) as the indicator for water availability. Vegetation sensitivity to water availability is derived from a principal components regression that identifies the importance of changes in AET/PET in driving changes in the enhanced vegetation index (EVI). See ref. ${ }^{49}$ for full methods.

Justification:

To the authors' knowledge, this is the only existing dataset of global vegetation productivity sensitivity to water availability anomalies.

\section{Environmental flow sensitivity to groundwater head decline}

Data source: de Graaf et al. ${ }^{50}$

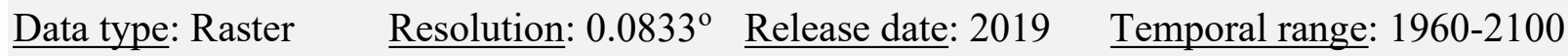
Description:

An estimate of the head decline at which environmental flow needs are first transgressed due to groundwater pumping in a physically based groundwater-surface water model over a 19602100 simulation period. Results are averaged at the HydroSHEDS level 6 scale.

Justification:

To the authors' knowledge, this is the only existing global dataset of environmental flow sensitivity to pumping-driven changes in groundwater head. 


\section{Adaptive capacity} Data source: Varis et al. ${ }^{14}$

Data type: Raster $\quad$ Resolution: $0.0833^{\circ}$ Release date: 2019 Temporal range: 2015

\section{Description:}

As described in Varis et al., adaptive capacity represents the ability of the social-ecological system to 'respond to disturbances' and 'implement adaptation strategies to cope with current or future events.' The dataset is a composite of normalized government effectiveness, GDP per capita at PPP, and human development index. See ref. ${ }^{14}$ for full methods.

\section{Justification:}

To the authors' best knowledge, this is the only existing dataset of adaptive capacity, in a socioecological systems context, at the global scale.

\section{Precipitation}

\section{Data sources:}

- Global Precipitation Climatology Centre (GPCC) Full Data Monthly Product Version $2018^{66}$

- Climatic Research Unit (CRU) Timeseries v3.26 ${ }^{67}$

- University of Delaware (UDEL) Air Temperature and Precipitation ${ }^{68}$

\section{Data type: NetCDF $\quad \underline{\text { Resolution: } 0.5^{\circ}} \quad$ Temporal Range: 1972-2001}

Description:

Historical monthly precipitation data at $0.5^{\circ}$ resolution over the 30 -year period preceding the GRACE mission.

Justification:

We base our precipitation data selection on the review by Sun et al. ${ }^{69}$, and select all precipitation products at $0.5^{\circ}$ resolution that span the required time period (1972-2001). This limits the precipitation inputs to the GPCC, CRU, UDEL, and PREC/L (Precipitation Reconstruction Land) gauge based datasets, excludes all satellite products. While the JRA-55 reanalysis product fits the criteria, we follow the review's commentary that reanalysis products tend to overestimate precipitation and decide to limit our precipitation inputs to the GPCC, CRU, UDEL, and PREC/L datasets. We were unable to reproduce the annual time series of the PREC/L dataset in comparison to the timeseries shown in Sun et al. ${ }^{69}$ 's and thus also exclude the PREC/L dataset.

\section{World regions}

Data source: Model of Agricultural Production and its Impact on the Environment (MAgPIE) ${ }^{70}$ Data type: Tabular Resolution: N/A Release date: N/A Temporal range: N/A Description:

A categorization of the world's nations into 10 characteristic regions. Justification:

We use the world regions used in MAgPIE in place of other common world region determinations (such as World Bank world regions) due to their consideration of Western Europe as separate from Former Soviet States, and in the division of the World Bank's East Asia and Pacific region into Centrally Planned Asia, Pacific Asia, and OECD (wealthy) Pacific Nations. 


\section{M-5. Code availability}

788 All code can be found on GitHub (github.com/XanderHuggins/ws-hd GRACE) or can be made 789 available from X.H. upon request. Analysis was performed using the R project for statistical 790 computing $^{71}$, using the raster ${ }^{72}, \operatorname{rgdal}^{73}$, spatstat ${ }^{74}$ and Weighted.Desc.Stats ${ }^{75}$ packages. Figures 791 were prepared using ggplot $2^{76}$ and tmap ${ }^{77}$ packages and assembled in Affinity Designer 792 [https://affinity.serif.com/en-gb/designer/]. 


\section{References:}

1. Rodell, M. et al. Emerging trends in global freshwater availability. Nature 557, 651-659 (2018).

2. Famiglietti, J. S. The global groundwater crisis. Nat. Clim. Chang. 4, 945-948 (2014).

3. Smakhtin, V., Revenga, C. \& Döll, P. A pilot global assessment of environmental water requirements and scarcity. Water Int. 29, 307-317 (2004).

4. Richter, B. D., Davis, M. M., Apse, C. \& Konrad, C. A presumptive standard for environmental flow protection. River Res. Appl. 28, 1312-1321 (2012).

5. Gleick, P. H. Basic Water Requirements for Human Activities: Meeting Basic Needs. Water Int. 21, 83-92 (1996).

6. Postel, S. L., Daily, G. C. \& Ehrlich, P. R. Human Appropriation of Renewable Fresh Water. Science 271, 785-788 (1996).

7. Döll, P. \& Siebert, S. Global modeling of irrigation water requirements. Water Resour. Res. 38, 8-1-8-10 (2002).

8. Oki, T. \& Kanae, S. Global Hydrological Cycles and World Water Resources. Science 313, 1068-1072 (2006).

9. Abbott, B. W. et al. Human domination of the global water cycle absent from depictions and perceptions. Nat. Geosci. 12, 533-540 (2019).

10. Haddeland, I. et al. Global water resources affected by human interventions and climate change. Proc. Natl. Acad. Sci. U. S. A. 111, 3251-3256 (2014).

11. Rockström, J. et al. A safe operating space for humanity. Nature 461, 472-475 (2009).

12. Steffen, W. et al. Planetary boundaries: Guiding human development on a changing planet. doi:10.1126/science. 1259855

13. Bakker, K. \& Morinville, C. The governance dimensions of water security: A review. Philos. Trans. R. Soc. A Math. Phys. Eng. Sci. 371, (2013).

14. Varis, O., Taka, M. \& Kummu, M. The Planet's Stressed River Basins: Too Much Pressure or Too Little Adaptive Capacity? Earth's Futur. 7, 1118-1135 (2019).

15. Rica, M., Petit, O. \& Elena, L.-G. Understanding groundwater governance through a social ecological system framework - relevance and limits. in Advances in Groundwater Governance 55-72 (CRC Press, 2019). doi:10.1201/9781315210025-3

16. Maass, M. Integrating food-water-energy research through a socio-ecosystem approach. Front. Environ. Sci. 5, 1-8 (2017).

17. Chapin, F. S., Kofinas, G. P. \& Folke, C. Principles of ecosystem stewardship: Resiliencebased natural resource management in a changing world. Princ. Ecosyst. Steward. Resilience-Based Nat. Resour. Manag. a Chang. World 1-409 (2009). doi:10.1007/978-0387-73033-2

18. von Stackelberg, K. Ecosystem Resilience on Human Terms. Integr. Environ. Assess. Manag. 14, 598-600 (2018).

19. Ostrom, E. A General Framework for Analyzing Sustainability of Socio-Ecological Systems. Science 325, 419-422 (2009).

20. Alcamo, J. et al. Development and testing of the WaterGAP 2 global model of water use and availability. Hydrol. Sci. J. 48, 317-338 (2003).

21. Sutanudjaja, E. H. et al. PCR-GLOBWB 2: A 5 arcmin global hydrological and water resources model. Geosci. Model Dev. 11, 2429-2453 (2018).

22. Fan, Y., Li, H. \& Miguez-Macho, G. Global Patterns of Groundwater Table Depth. Science 339, 940-943 (2013). 
23. Hobeichi, S., Abramowitz, G., Evans, J. \& Beck, H. E. Linear Optimal Runoff Aggregate (LORA): a global gridded synthesis runoff product. Hydrol. Earth Syst. Sci. 23, 851-870 (2019).

24. Ghiggi, G., Humphrey, V., Seneviratne, S. I. \& Gudmundsson, L. GRUN: an observationbased global gridded runoff dataset from 1902 to 2014. Earth Syst. Sci. Data 11, 16551674 (2019).

25. Scanlon, B. R. et al. Global models underestimate large decadal declining and rising water storage trends relative to GRACE satellite data. Proc. Natl. Acad. Sci. U. S. A. E1080E1089 (2018). doi:10.1073/pnas.1704665115

26. Kummu, M., Ward, P. J., De Moel, H. \& Varis, O. Is physical water scarcity a new phenomenon? Global assessment of water shortage over the last two millennia. Environ. Res. Lett. 5, (2010).

27. Kummu, M. et al. The world's road to water scarcity: shortage and stress in the 20th century and pathways towards sustainability. Sci. Rep. 6, 38495 (2016).

28. Falkenmark, M., Lundqvist, J. \& Widstrand, C. Macro-scale water scarcity requires micro-scale approaches: Aspects of vulnerability in semi-arid development. Nat. Resour. Forum 258-267 (1989).

29. Vorosmarty, C. J. Global Water Resources: Vulnerability from Climate Change and Population Growth. Science 289, 284-288 (2000).

30. Gleeson, T., Wada, Y., Bierkens, M. F. P. \& van Beek, L. P. H. Water balance of global aquifers revealed by groundwater footprint. Nature 488, 197-200 (2012).

31. Ohlsson, L. Water conflicts and social resource scarcity. Phys. Chem. Earth, Part B Hydrol. Ocean. Atmos. 25, 213-220 (2000).

32. Vörösmarty, C. J. et al. Global threats to human water security and river biodiversity. Nature 467, 555-561 (2010).

33. Padowski, J. C., Gorelick, S. M., Thompson, B. H., Rozelle, S. \& Fendorf, S. Assessment of human-natural system characteristics influencing global freshwater supply vulnerability. Environ. Res. Lett. 10, (2015).

34. Gain, A. K., Giupponi, C. \& Wada, Y. Measuring global water security towards sustainable development goals. Environ. Res. Lett. 11, (2016).

35. Sullivan, C. A. Calculating a Water Poverty Index. World Dev. 30, 1195-1210 (2002).

36. Tapley, B. D., Bettadpur, S., Watkins, M. \& Reigber, C. The gravity recovery and climate experiment: Mission overview and early results. Geophys. Res. Lett. 31, n/a-n/a (2004).

37. Sultan, M. et al. Assessment of age, origin, and sustainability of fossil aquifers: A geochemical and remote sensing-based approach. J. Hydrol. 576, 325-341 (2019).

38. Scanlon, B. R. et al. Hydrologic implications of GRACE satellite data in the Colorado River Basin. Water Resour. Res. 51, 9891-9903 (2015).

39. Thomas, B. F. et al. GRACE Groundwater Drought Index: Evaluation of California Central Valley groundwater drought. Remote Sens. Environ. 198, 384-392 (2017).

40. Richey, A. S. et al. Quantifying renewable groundwater stress with GRACE. Water Resour. Res. 51, 5217-5238 (2015).

41. Voss, K. A. et al. Groundwater depletion in the Middle East from GRACE with implications for transboundary water management in the Tigris-Euphrates-Western Iran region. 49, 904-914 (2013).

42. Tapley, B. D. et al. Contributions of GRACE to understanding climate change. Nat. Clim. Chang. 9, 358-369 (2019). 
43. Damkjaer, S. \& Taylor, R. The measurement of water scarcity: Defining a meaningful indicator. Ambio 46, 513-531 (2017).

44. Döll, P. et al. Impact of water withdrawals from groundwater and surface water on continental water storage variations. J. Geodyn. 59-60, 143-156 (2012).

45. Wada, Y., Van Beek, L. P. H. \& Bierkens, M. F. P. Nonsustainable groundwater sustaining irrigation: A global assessment. Water Resour. Res. 48, (2012).

46. Guppy, L., Uyttendaele, P., Villholth, K. G. \& Smakhtin, V. Groundwater and Sustainable Development Goals: Analysis of Interlinkages. 1-23 (2018).

47. Hall, J. W. et al. Coping with the curse of freshwater availability. Science 346, 429-430 (2014).

48. Olson, D. M. \& Dinerstein, E. The Global 200 : Priority Ecoregions for Global Conservation. Ann. Missouri Bot. Gard. 89, 199-224 (2002).

49. Seddon, A. W. R., Macias-Fauria, M., Long, P. R., Benz, D. \& Willis, K. J. Sensitivity of global terrestrial ecosystems to climate variability. Nature 531, 229-232 (2016).

50. de Graaf, I. E. M., Gleeson, T., (Rens) van Beek, L. P. H., Sutanudjaja, E. H. \& Bierkens, M. F. P. Environmental flow limits to global groundwater pumping. Nature 574, 90-94 (2019).

51. Stahl, K., Moore, R. D., Shea, J. M., Hutchinson, D. \& Cannon, A. J. Coupled modelling of glacier and streamflow response to future climate scenarios. Water Resour. Res. 44, 113 (2008).

52. Millington, R., Cox, P. M., Moore, J. R. \& Yvon-Durocher, G. Modelling ecosystem adaptation and dangerous rates of global warming. Emerg. Top. Life Sci. 3, 221-231 (2019).

53. Turner, B. L. et al. A framework for vulnerability analysis in sustainability science. Proc. Natl. Acad. Sci. U. S. A. 100, 8074-8079 (2003).

54. Lakshmi, V. Beyond GRACE: Using Satellite Data for Groundwater Investigations. Groundwater 54, 615-618 (2016).

55. Reager, J. T., Thomas, B. F. \& Famiglietti, J. S. River basin flood potential inferred using GRACE gravity observations at several months lead time. Nat. Geosci. 7, 588-592 (2014).

56. Reager, J. et al. Assimilation of GRACE Terrestrial Water Storage Observations into a Land Surface Model for the Assessment of Regional Flood Potential. Remote Sens. 7, 14663-14679 (2015).

57. Castle, S. L. et al. Groundwater depletion during drought threatens future water security of the Colorado River Basin. Geophys. Res. Lett. 41, 5904-5911 (2014).

58. Salmivaara, A. et al. Exploring the modifiable areal unit problem in spatial water assessments: A case of water shortage in Monsoon Asia. Water 7, 898-917 (2015).

59. Brakenridge, G. R. Global Active Archive of Large Flood Events. (2020).

60. CIESIN. Gridded Population of the World, Version 4 (GPWv4): Population Count. (2016).

61. Ramankutty, N., Evan, A. T., Monfreda, C. \& Foley, J. A. Farming the planet: 1. Geographic distribution of global agricultural lands in the year 2000. Global Biogeochem. Cycles 22, 1-19 (2008).

62. Cassidy, E. S., West, P. C., Gerber, J. S. \& Foley, J. A. Redefining agricultural yields: From tonnes to people nourished per hectare. Environ. Res. Lett. 8, (2013).

63. Siebert, S., Henrich, V., Frenken, K. \& Burke, J. Global Map of Irrigation Areas version 
5. (2013).

64. Kummu, M., Taka, M. \& Guillaume, J. H. A. Data from: Gridded global datasets for Gross Domestic Product and Human Development Index over 1990-2015. (2019). doi:10.5061/dryad.dk1j0

65. Kummu, M., Taka, M. \& Guillaume, J. H. A. Gridded global datasets for Gross Domestic Product and Human Development Index over 1990-2015. Sci. Data 5, 1-15 (2018).

66. Schneider, U., Becker, A., Finger, P., Meyer-Christoffer, A. \& Ziese, M. GPCC Full Data Monthly Product Version 2018 at 0.5 : Monthly Land-Surface Precipitation from RainGauges built on GTS-based and Historical Data. (2018). doi:10.5676/DWD_GPCC/FD_M_V2018_050

67. Harris, I., Jones, P. D., Osborn, T. J. \& Lister, D. H. Updated high-resolution grids of monthly climatic observations - the CRU TS3.10 Dataset. Int. J. Climatol. 34, 623-642 (2014).

68. Willmott, C. J. \& Matsuura, K. Terrestrial Air Temperature and Precipitation: Monthly and Annual Time Series (1950 - 1999). (2001).

69. Sun, Q. et al. A Review of Global Precipitation Data Sets: Data Sources, Estimation, and Intercomparisons. Rev. Geophys. 56, 79-107 (2018).

70. Dietrich, J. et al. MAgPIE - An Open Source land-use modeling framework - Version 4.0. (2018). doi:10.5281/zenodo.1418752

71. R Core Team. R: A language and environment for statistical computing. (2019).

72. Hijmans, R. J. raster: Geographic Data Analysis and Modeling. (2019).

73. Bivand, R. et al. rgdal: Bindings for the 'Geospatial' Data Abstration Library. (2019).

74. Baddely, A., Turner, R. \& Rubak, E. spatstat: Spatial Point Pattern Analysis, ModelFitting, Simulation, Tests. (2020).

75. Parchami, A. Weighted.Desc.Stat: Weighted Descriptive Statistics. (2016).

76. Wickham, H. ggplot2: Elegant Graphics for Data Analysis. (2016).

77. Tennekes, M. et al. tmap: Thematic Maps. (2020). 
Supplementary information:

Table of Contents:

SI-1. Figures

SI-2. Tables

SI-3. Author contributions

\section{SI-1. Figures:}
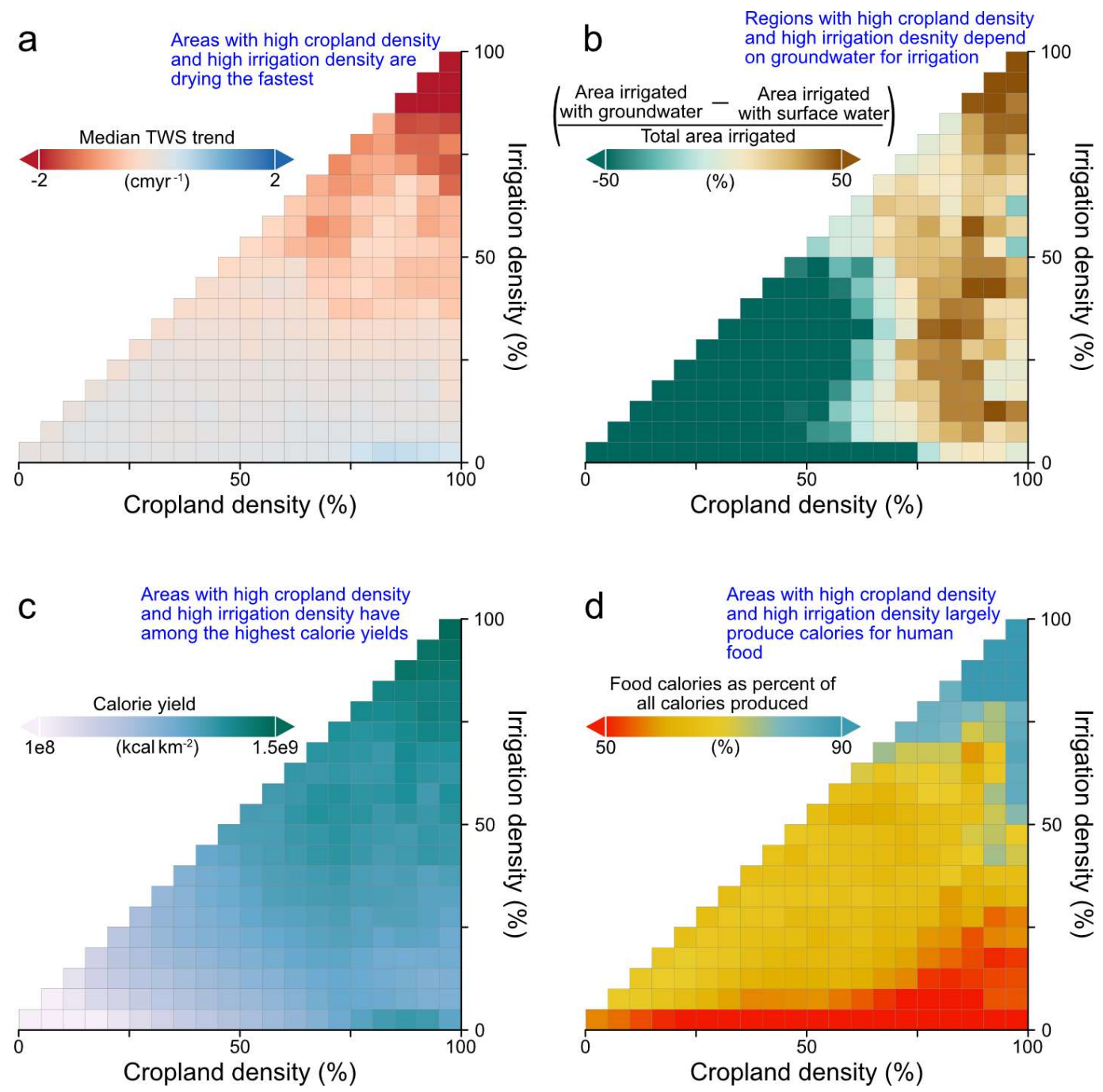

Supplementary Fig. 1. Supplemental figures for the agricultural dimension. (a) Relationship between cropland density (x-axis), area equipped for irrigation (y-axis), and freshwater availability trends (color). The relationship between cropland density and irrigation density with respect to (b) irrigation water source, (c) caloric crop yield, and (d) crop production for human food as a percentage of total crop production (as measured in calories). Plots (a) and (b) show area-weighted median values per individual combinations of cropland density and irrigation density (categorized at 5\% intervals), while plots (c) and (d) sum calorie production and land area within each combination of cropland and irrigation densities to calculate results. 


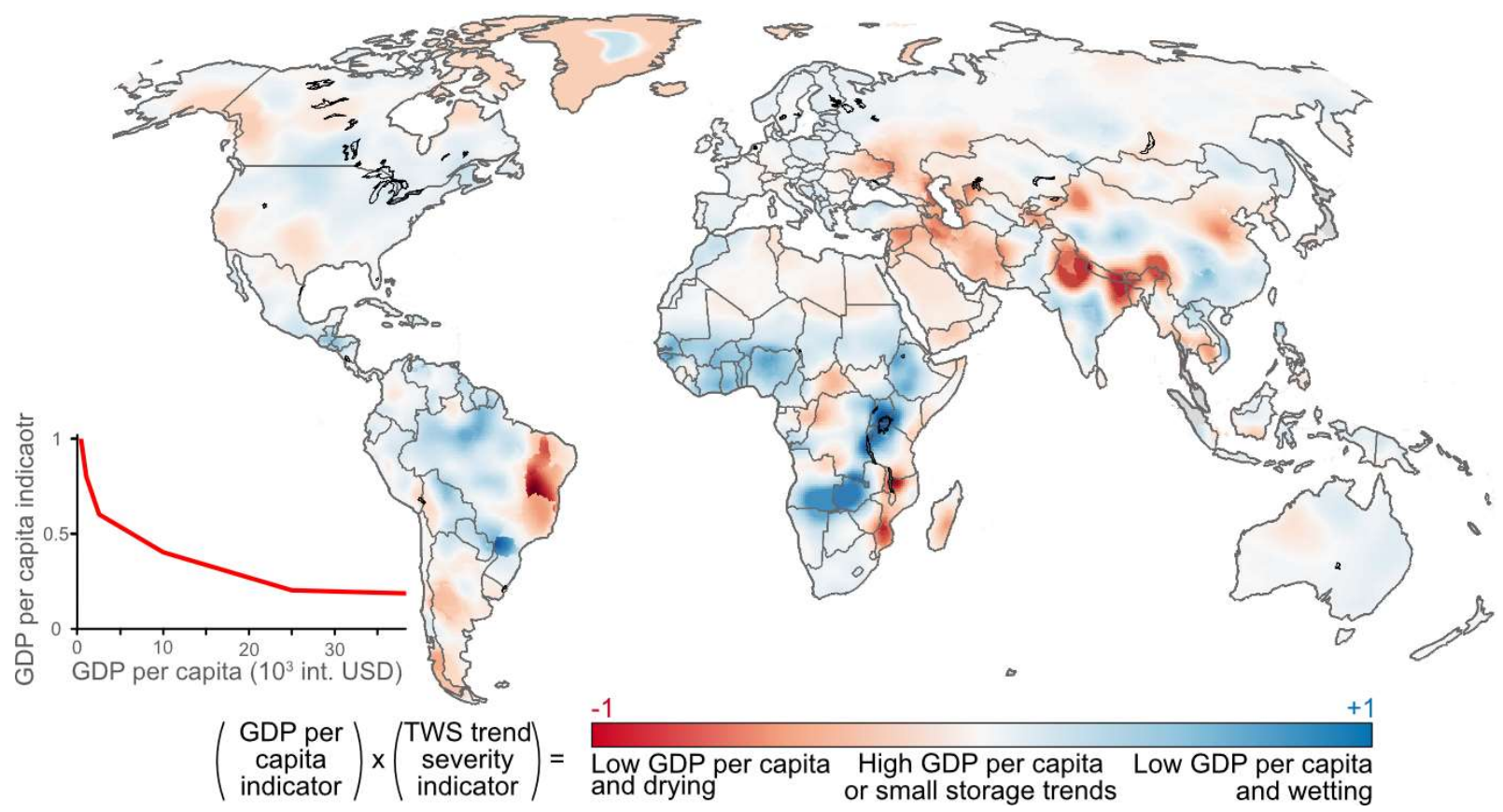

971 Supplementary Fig. 2. The relationship between GDP per capita and water availability trend 972 severity. GDP is measured in 2011 international USD and evaluated at sub-national administrative 973 units.

a

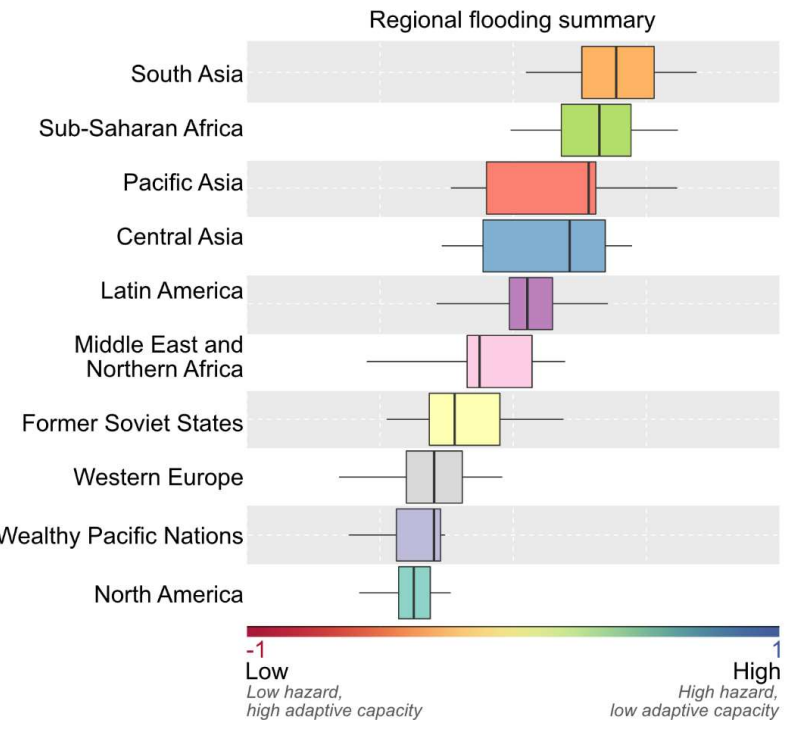

b

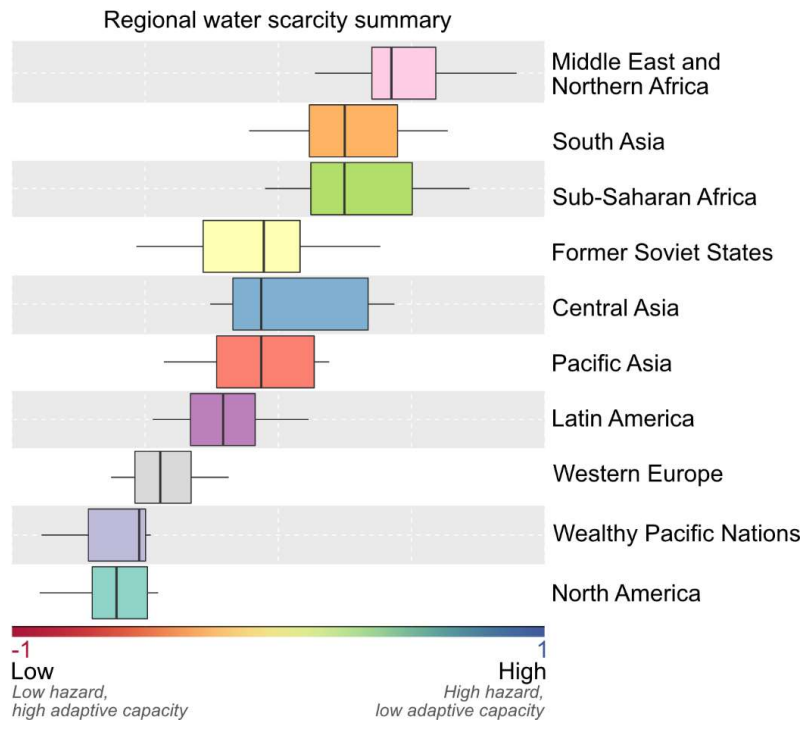

Supplementary Fig. 3. The regional vulnerability distributions to (a) flooding and (b) water scarcity. Boxplots summarize each world region's population-based vulnerability distribution showing the $5^{\text {th }}, 25^{\text {th }}, 50^{\text {th }}, 75^{\text {th }}$, and $95^{\text {th }}$ population-weighted vulnerability percentiles to flooding and water scarcity. 

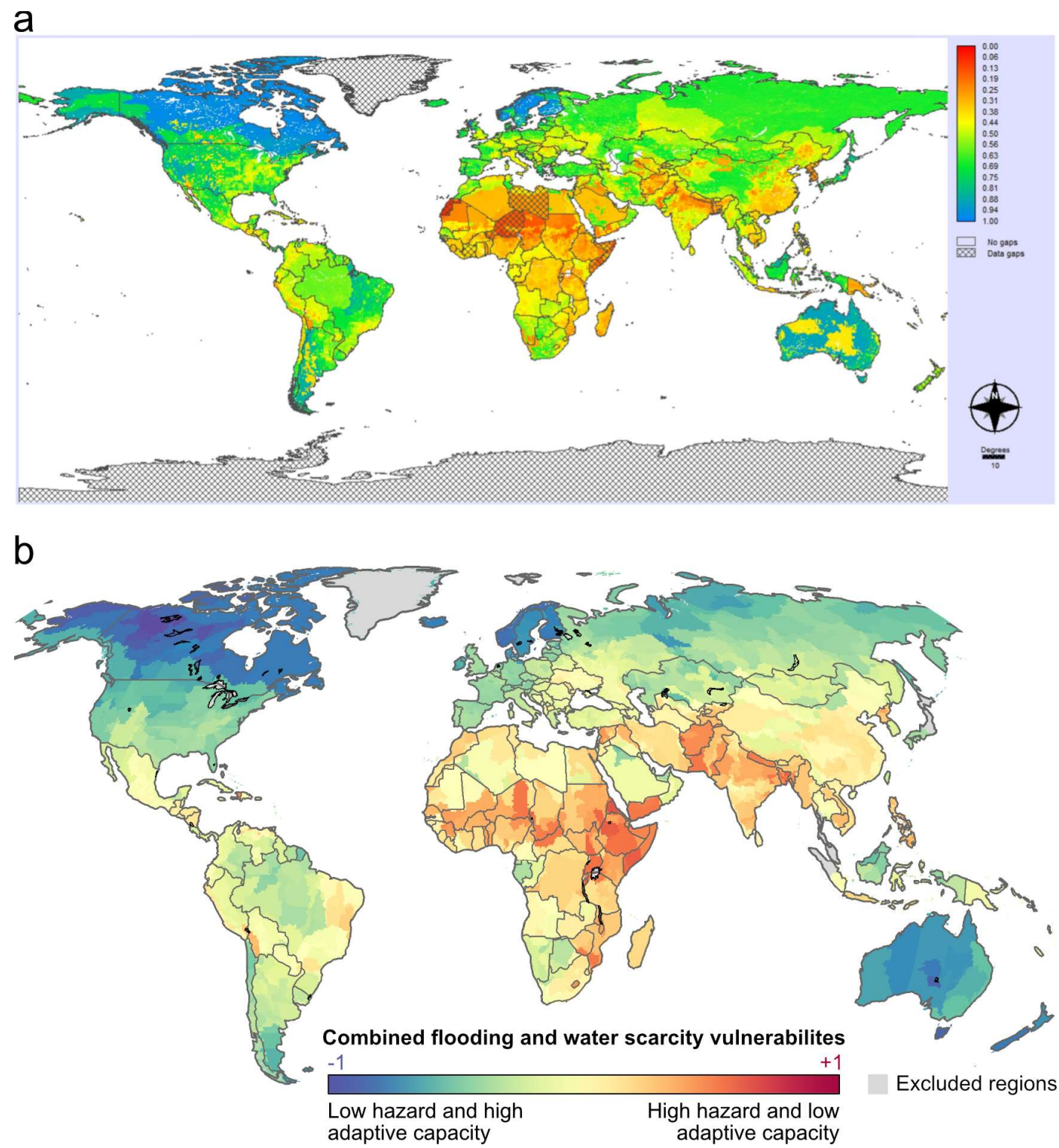

976 Supplementary Fig. 4. A comparison of the combined vulnerability assessment to the global 977 water security assessment of Gain et al. ${ }^{34}$. (a) Gain et al.'s aggregated global water security index, 978 where values near 0 (red) represent low water security and values near 1 (blue) indicate high water 979 security. (b) An equal-weight combination of our water scarcity and flooding vulnerability 980 assessments, where values near +1 (red) represent high combined vulnerability and values near -1 981 (blue) indicate low combined vulnerability. 
a
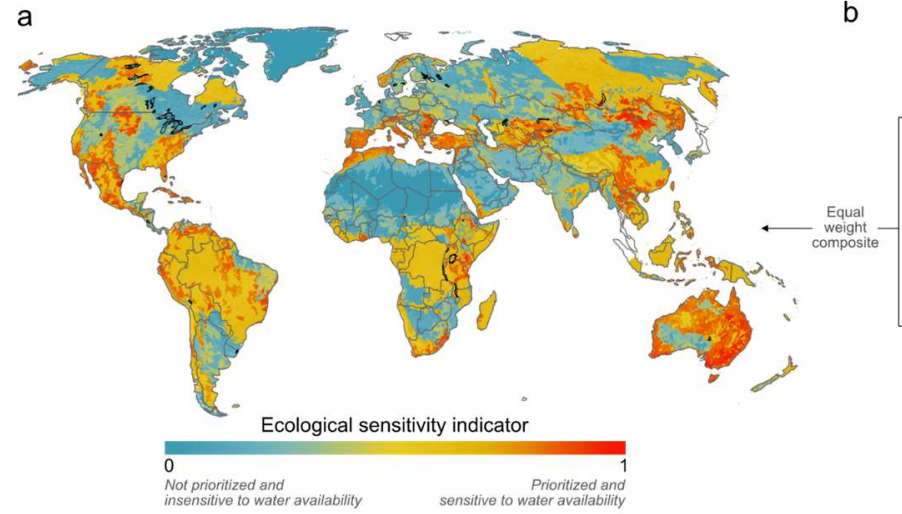

C

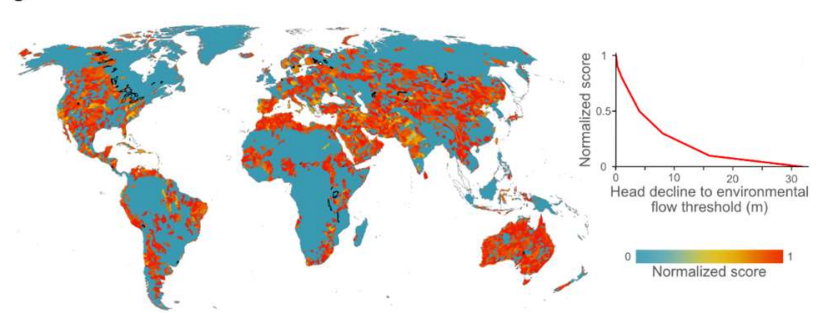

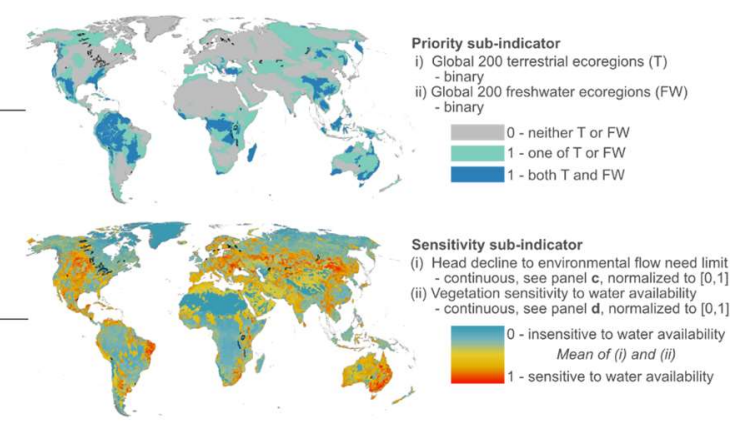

d

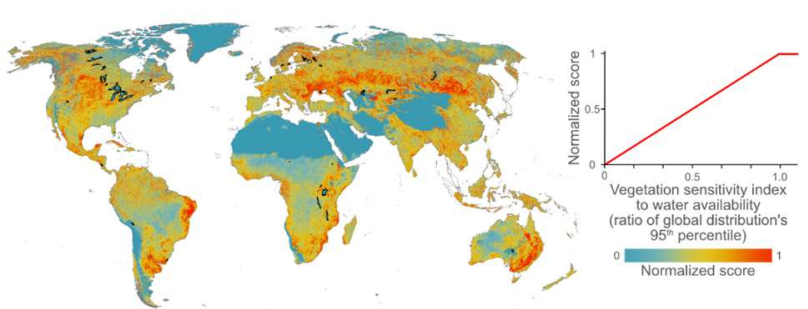

Supplementary Fig. 5. The derivation of the ecological dimension indicator. (a) The final indicator, created by equally weighting the priority and sensitivity sub-indicators (shown in b). The sensitivity sub-indicator is comprised of the (c) normalized environmental flow sensitivity to groundwater head decline and (d) normalized vegetation sensitivity to soil moisture availability. The normalization functions for (c) and (d) are both shown. 

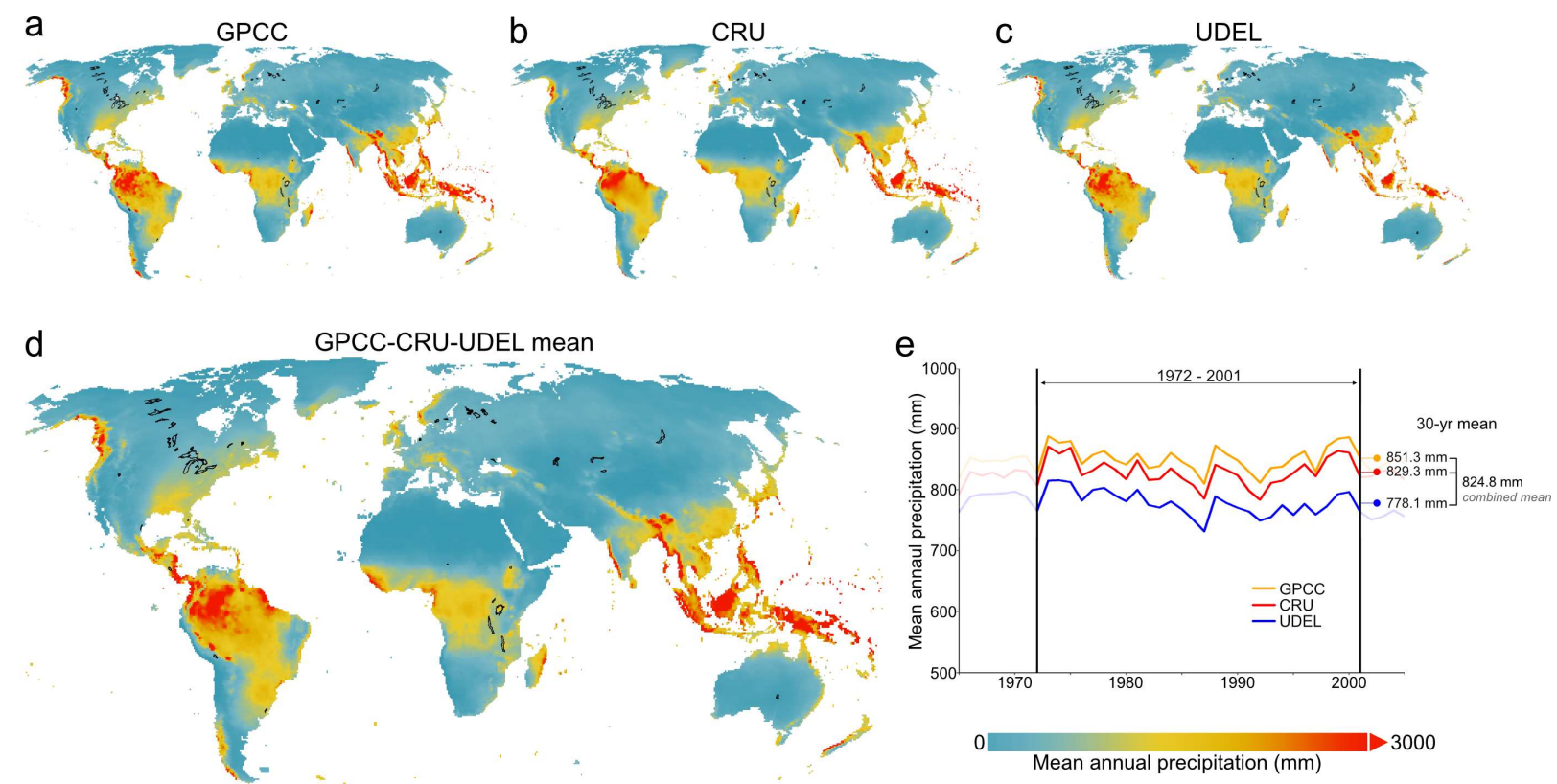

Supplementary Fig. 6. Global precipitation datasets used to calculate the long-term mean annual precipitation over $1972-2001$ at $0.5^{\circ}$. The long-term mean annual precipitation results for the (a) GPCC, (b) CRU, (c) UDEL and (d) combined datasets. (e) Mean annual precipitation time series for each precipitation product, calculated for all land area excluding Antarctica, with 30-year period averages shown on the right. Note that the combined average is not the average of the three reported 30-year means as not all datasets covered the same extent and thus not all datasets were averaged in some regions. 

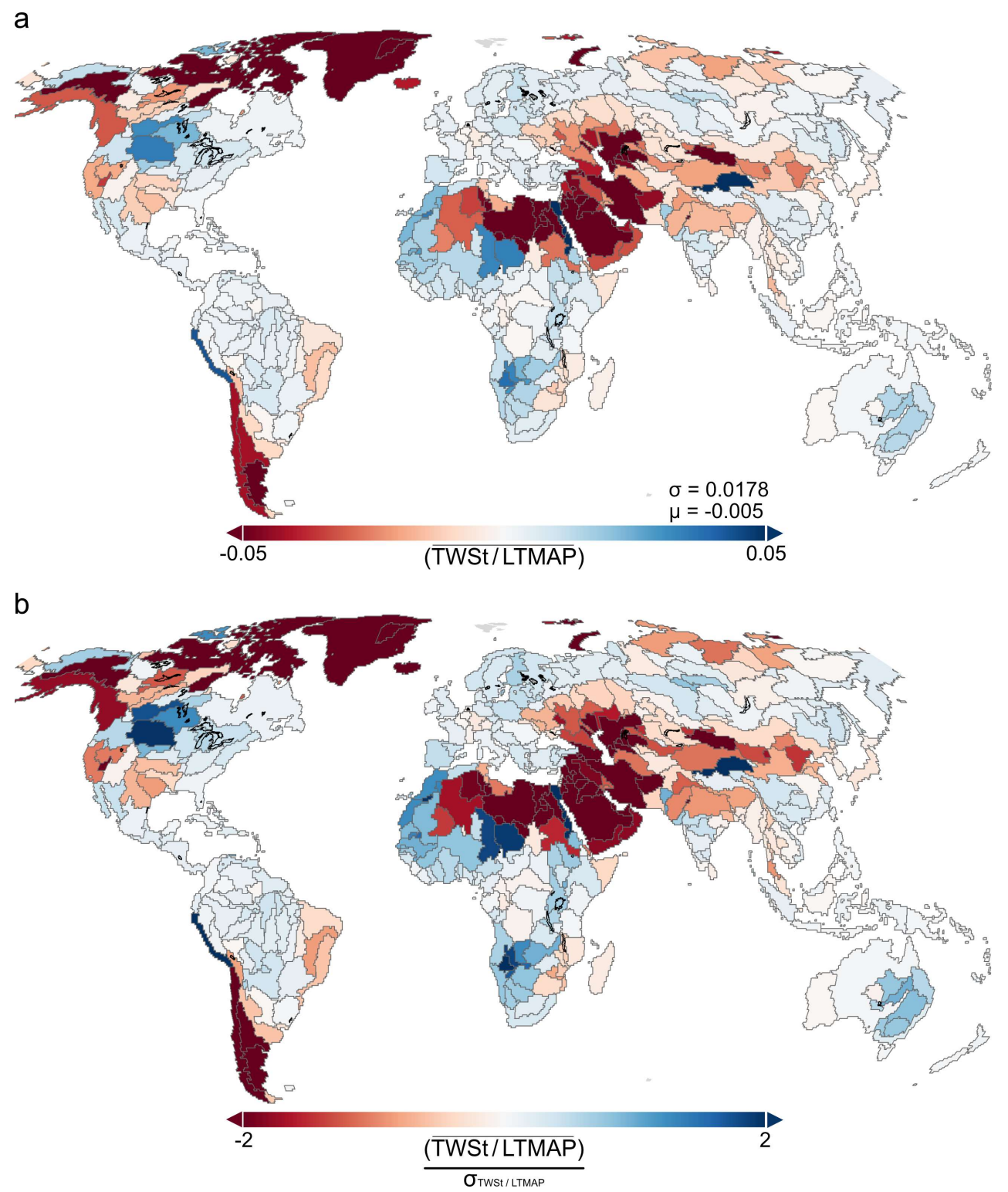

Supplementary Fig. 7. Normalizing the TWS trends by long-term mean annual precipitation per modified Food Production Unit. (a) TWS trends (TWSt) divided by mean annual precipitation (LTMAP), and area-weighted averaged over each modified Food Production Unit. (b) The

999 TWSt/LTMAP results normalized by standard deviation, which form the basis of the hazard 1000 modification process. 

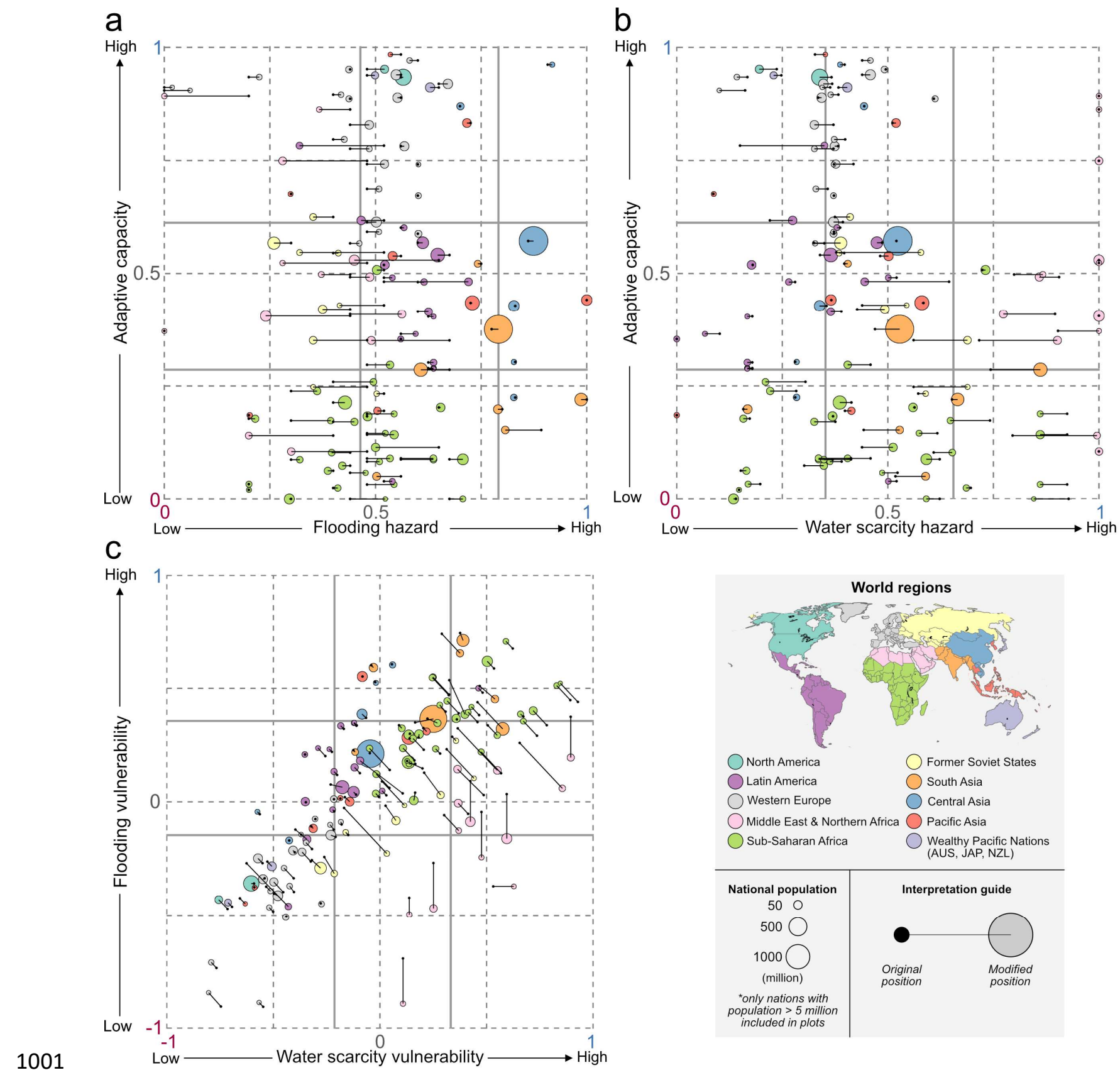

Supplementary Fig. 8. The effect of the hazard modification process on the national results of the (a) flooding, (b) water scarcity, and (c) combined vulnerability assessments. National plotting coordinates are determined based on population-weighted median values, with the size scaled by population. Note that the TWS modification process only impacts hazard levels, and thus modifications are restricted to the horizontal plane in panels a and $\mathrm{b}$. 


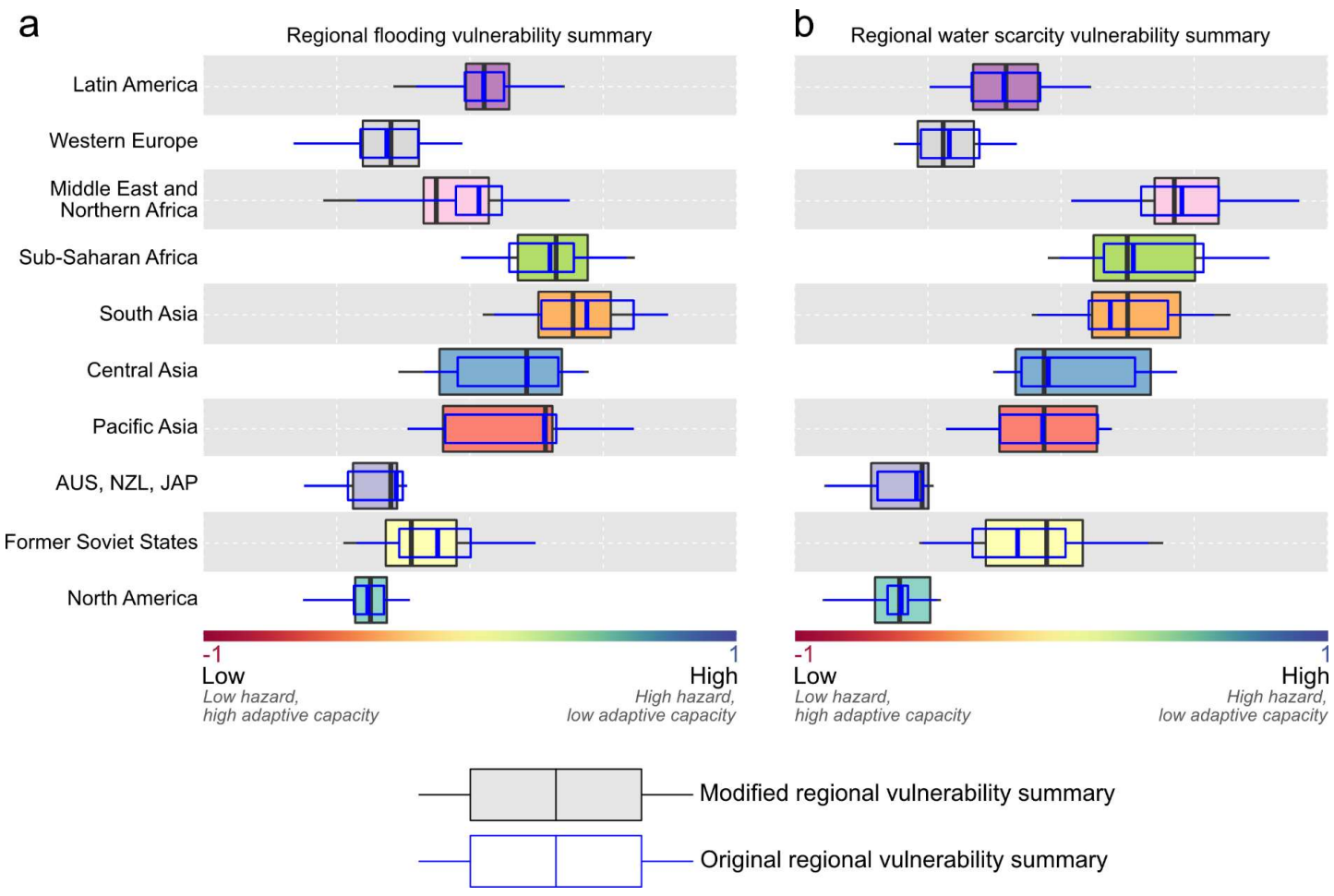

1008 Supplementary Fig. 9. The effect of the hazard modification process on the regional vulnerability 1009 results for (a) flooding and (b) water scarcity.

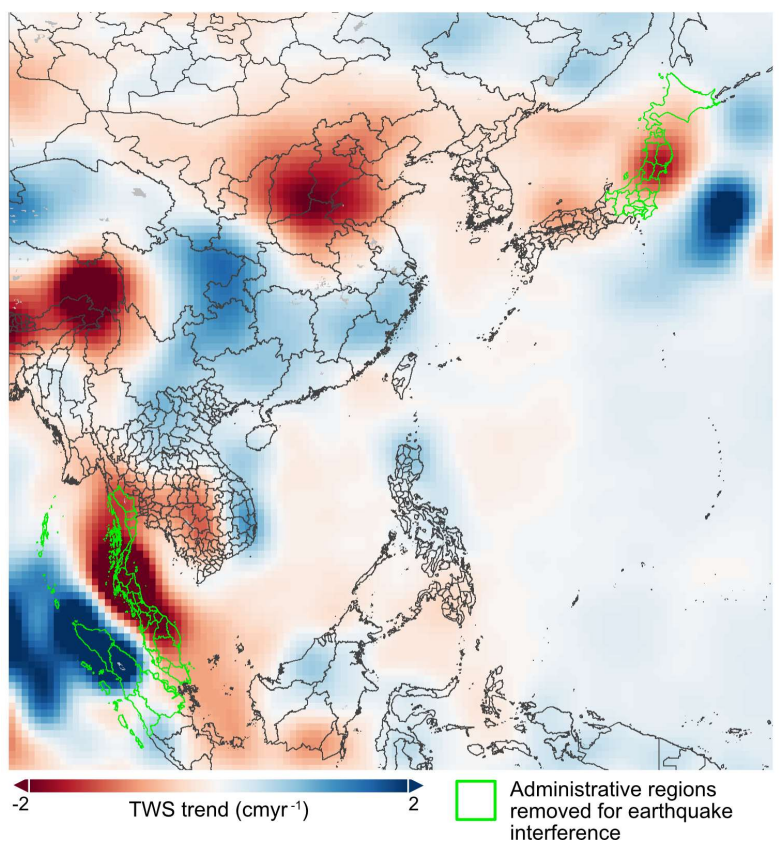

Supplementary Fig. 10. Administrative areas outlining regions removed from all analysis due to seismic activity interference. Northern Sumatra and the Malay Peninsula are removed due to interference from the 2004 Indian Ocean earthquake, while Tohoku and surrounding regions of Japan are removed due to interference from the 2011 Tohoku earthquake. Administrative regions were selected for removal based on subjective decisions regarding where the apparent earthquake caused trends dissipate. 


\section{SI-2. Tables:}

1017 Supplementary Table 1: The human population distribution across all combinations of water 1018 shortage and water availability trend classifications. Colored shading corresponds to the legend in 1019 Figure $4 \mathrm{~b}$, and the yellow box indicates regions of water shortage and drying conditions. Values 1020 in parentheses represent percentages.

\begin{tabular}{|c|c|c|c|c|c|}
\hline $\begin{array}{c}\text { Water } \\
\text { shortage } \\
\text { class } \\
\left(\mathrm{m}^{3} \mathrm{cap}^{-1} \mathrm{yr}^{-1}\right) \\
\end{array}$ & $\begin{array}{l}\text { Severe } \\
\text { drying } \\
\text { (million) }\end{array}$ & $\begin{array}{l}\text { Moderate } \\
\text { drying } \\
\text { (million) }\end{array}$ & $\begin{array}{c}\text { Static } \\
\text { conditions } \\
\text { (million) }\end{array}$ & $\begin{array}{l}\text { Moderate } \\
\text { wetting } \\
\text { (million) }\end{array}$ & $\begin{array}{l}\text { Severe } \\
\text { wetting } \\
\text { (million) }\end{array}$ \\
\hline $\begin{array}{c}\text { Extreme } \\
\text { shortage } \\
(<500)\end{array}$ & $\begin{array}{l}84.0 \\
(1.2)\end{array}$ & $\begin{array}{l}500.8 \\
(6.9)\end{array}$ & $\begin{array}{l}408.7 \\
(5.7)\end{array}$ & $\begin{array}{c}269.3 \\
(3.7)\end{array}$ & $\begin{array}{l}13.0 \\
(0.2)\end{array}$ \\
\hline $\begin{array}{c}\text { High } \\
\text { shortage } \\
(500-1000) \\
\end{array}$ & $\begin{array}{l}19.7 \\
(0.3)\end{array}$ & $\begin{array}{l}215.6 \\
(3.0)\end{array}$ & $\begin{array}{r}421.9 \\
(5.8)\end{array}$ & $\begin{array}{l}176.8 \\
(2.4)\end{array}$ & $\begin{array}{c}0.5 \\
(0.0)\end{array}$ \\
\hline $\begin{array}{c}\text { Moderate } \\
\text { shortage } \\
(1000-1700)\end{array}$ & $\begin{array}{l}219.8 \\
(3.0)\end{array}$ & $\begin{array}{l}398.9 \\
(5.5)\end{array}$ & $\begin{array}{l}1021.4 \\
(14.1)\end{array}$ & $\begin{array}{l}401.3 \\
(5.6)\end{array}$ & $\begin{array}{l}<0.1 \\
(0.0)\end{array}$ \\
\hline $\begin{array}{c}\text { Near } \\
\text { shortage } \\
(1000-10000)\end{array}$ & $\begin{array}{l}33.6 \\
(0.5)\end{array}$ & $\begin{array}{l}364.9 \\
(5.1)\end{array}$ & $\begin{array}{c}1388.8 \\
(19.2)\end{array}$ & $\begin{array}{l}667.2 \\
(9.2)\end{array}$ & $\begin{array}{c}2.4 \\
(0.0)\end{array}$ \\
\hline $\begin{array}{c}\text { No shortage } \\
(>10000)\end{array}$ & $\begin{array}{c}1.5 \\
(0.0) \\
\end{array}$ & $\begin{array}{l}60.3 \\
(0.8) \\
\end{array}$ & $\begin{array}{c}408.2 \\
(5.7) \\
\end{array}$ & $\begin{array}{l}129.5 \\
(1.8) \\
\end{array}$ & $\begin{array}{c}2.1 \\
(0.0)\end{array}$ \\
\hline No Data & $\begin{array}{l}<0.1 \\
(0.0)\end{array}$ & $\begin{array}{c}0.2 \\
(0.0)\end{array}$ & $\begin{array}{c}9.6 \\
(0.1)\end{array}$ & $\begin{array}{c}0.4 \\
(0.0)\end{array}$ & $\begin{array}{l}<0.1 \\
(0.0)\end{array}$ \\
\hline Total & $\begin{array}{l}358.7 \\
(5.0)\end{array}$ & $\begin{array}{l}1540.6 \\
(21.3)\end{array}$ & $\begin{array}{c}3658.7 \\
(50.7)\end{array}$ & $\begin{array}{l}1644.6 \\
(22.8)\end{array}$ & $\begin{array}{l}18.1 \\
(0.3)\end{array}$ \\
\hline
\end{tabular}


1021 Supplementary Table 2: Global crop production, measured in calories, relative to water 1022 availability trends and water shortage classes. Red box indicates regions of water shortage and 1023 drying trends as referred to in the main text. Values in parentheses represent percentages.

\begin{tabular}{|c|c|c|c|c|c|}
\hline $\begin{array}{l}\text { Water shortage clas } \\
\qquad\left(\mathrm{m}^{3} \mathrm{cap}^{-1} \mathrm{yr}^{-1}\right)\end{array}$ & $\begin{array}{c}\text { Severe drying } \\
\text { (trillion kcal) }\end{array}$ & $\begin{array}{c}\text { Moderate drying } \\
\text { (trillion kcal) }\end{array}$ & $\begin{array}{l}\text { Static conditions } \\
\text { (trillion kcal) }\end{array}$ & $\begin{array}{c}\text { Moderate } \\
\text { wetting } \\
\text { (trillion kcal) }\end{array}$ & $\begin{array}{c}\text { Severe wetting } \\
\text { (trillion kcal) }\end{array}$ \\
\hline \multicolumn{6}{|c|}{ Food calories ( $54 \%$ of all calories; red box contains $20.1 \%$ of food calories) } \\
\hline $\begin{array}{c}\text { Extreme } \\
\text { shortage } \\
(<500)\end{array}$ & $\begin{array}{l}116.1 \\
(2.3)\end{array}$ & $\begin{array}{c}294.4 \\
(5.9)\end{array}$ & $\begin{array}{l}184.2 \\
(3.7)\end{array}$ & $\begin{array}{l}105.3 \\
(2.1)\end{array}$ & $\begin{array}{c}2.9 \\
(0.1)\end{array}$ \\
\hline $\begin{array}{c}\text { High } \\
\text { shortage }(500- \\
1000) \\
\end{array}$ & $\begin{array}{l}27.2 \\
(0.5)\end{array}$ & $\begin{array}{l}115.9 \\
(2.3)\end{array}$ & $\begin{array}{l}183.7 \\
(3.7)\end{array}$ & $\begin{array}{l}82.9 \\
(1.7)\end{array}$ & $\begin{array}{c}0.0 \\
(0.0)\end{array}$ \\
\hline $\begin{array}{c}\text { Moderate } \\
\text { shortage } \\
(1000-1700) \\
\end{array}$ & $\begin{array}{l}140.9 \\
(2.8)\end{array}$ & $\begin{array}{l}300.2 \\
(6.1)\end{array}$ & $\begin{array}{l}671.0 \\
(13.5)\end{array}$ & $\begin{array}{l}219.8 \\
(4.4)\end{array}$ & $\begin{array}{c}0.0 \\
(0.0)\end{array}$ \\
\hline $\begin{array}{l}\text { Near shortage } \\
(1000-10000)\end{array}$ & $\begin{array}{l}20.2 \\
(0.4) \\
\end{array}$ & $\begin{array}{c}287.8 \\
(5.8) \\
\end{array}$ & $\begin{array}{l}909.3 \\
(18.3)\end{array}$ & $\begin{array}{l}618.5 \\
(12.5)\end{array}$ & $\begin{array}{c}2.0 \\
(0.0) \\
\end{array}$ \\
\hline $\begin{array}{c}\text { No shortage } \\
(>10000)\end{array}$ & $\begin{array}{c}0.0 \\
(0.0)\end{array}$ & $\begin{array}{l}40.2 \\
(0.8) \\
\end{array}$ & $\begin{array}{l}418.5 \\
(8.4) \\
\end{array}$ & $\begin{array}{c}200.1 \\
(4.0) \\
\end{array}$ & $\begin{array}{l}13.4 \\
(0.3) \\
\end{array}$ \\
\hline No Data & $\begin{array}{c}0.0 \\
(0.0) \\
\end{array}$ & $\begin{array}{c}0.1 \\
(0.0)\end{array}$ & $\begin{array}{c}3.2 \\
(0.1) \\
\end{array}$ & $\begin{array}{c}0.0 \\
(0.0)\end{array}$ & $\begin{array}{c}0.0 \\
(0.0) \\
\end{array}$ \\
\hline \multicolumn{6}{|c|}{ Feed calories $(37 \%$ of all calories; red box contains $9.7 \%$ of feed calories) } \\
\hline $\begin{array}{c}\text { Extreme } \\
\text { shortage } \\
(<500)\end{array}$ & $\begin{array}{c}9.1 \\
(0.3)\end{array}$ & $\begin{array}{l}157.8 \\
(4.7)\end{array}$ & $\begin{array}{l}66.2 \\
(2.0)\end{array}$ & $\begin{array}{l}24.0 \\
(0.7)\end{array}$ & $\begin{array}{c}0.9 \\
(0.0)\end{array}$ \\
\hline $\begin{array}{c}\text { High } \\
\text { shortage }(500- \\
1000) \\
\end{array}$ & $\begin{array}{c}1.2 \\
(0.0)\end{array}$ & $\begin{array}{l}30.1 \\
(0.9)\end{array}$ & $\begin{array}{l}43.3 \\
(1.3)\end{array}$ & $\begin{array}{l}14.5 \\
(0.4)\end{array}$ & $\begin{array}{c}0.0 \\
(0.0)\end{array}$ \\
\hline $\begin{array}{c}\text { Moderate } \\
\text { shortage } \\
(1000-1700)\end{array}$ & $\begin{array}{c}8.4 \\
(0.2)\end{array}$ & $\begin{array}{l}120.3 \\
(3.6)\end{array}$ & $\begin{array}{l}397.3 \\
(11.7)\end{array}$ & $\begin{array}{l}82.5 \\
(2.4)\end{array}$ & $\begin{array}{c}0.0 \\
(0.0)\end{array}$ \\
\hline $\begin{array}{l}\text { Near shortage } \\
(1000-10000)\end{array}$ & $\begin{array}{c}3.5 \\
(0.1) \\
\end{array}$ & $\begin{array}{c}220.4 \\
(6.5) \\
\end{array}$ & $\begin{array}{l}783.8 \\
(23.2) \\
\end{array}$ & $\begin{array}{l}933.7 \\
(27.6)\end{array}$ & $\begin{array}{c}0.5 \\
(0.0) \\
\end{array}$ \\
\hline $\begin{array}{c}\text { No shortage } \\
(>10000)\end{array}$ & $\begin{array}{c}0.0 \\
(0.0) \\
\end{array}$ & $\begin{array}{l}14.5 \\
(0.4) \\
\end{array}$ & $\begin{array}{c}253.4 \\
(7.5) \\
\end{array}$ & $\begin{array}{c}206.6 \\
(6.1) \\
\end{array}$ & $\begin{array}{c}9.2 \\
(0.3) \\
\end{array}$ \\
\hline No Data & $\begin{array}{c}0.0 \\
(0.0)\end{array}$ & $\begin{array}{c}0.0 \\
(0.0)\end{array}$ & $\begin{array}{c}0.4 \\
(0.0)\end{array}$ & $\begin{array}{c}0.0 \\
(0.0)\end{array}$ & $\begin{array}{c}0.0 \\
(0.0)\end{array}$ \\
\hline \multicolumn{6}{|c|}{ Nonfood calories ( $8 \%$ of all calories; red box contains $13.4 \%$ of nonfood calories) } \\
\hline $\begin{array}{c}\text { Extreme } \\
\text { shortage } \\
(<500)\end{array}$ & $\begin{array}{c}5.2 \\
(0.7)\end{array}$ & $\begin{array}{l}43.4 \\
(5.6)\end{array}$ & $\begin{array}{l}21.2 \\
(2.7)\end{array}$ & $\begin{array}{l}14.5 \\
(1.9)\end{array}$ & $\begin{array}{c}0.4 \\
(0.1)\end{array}$ \\
\hline $\begin{array}{c}\text { High } \\
\text { shortage }(500- \\
1000)\end{array}$ & $\begin{array}{c}1.5 \\
(0.2)\end{array}$ & $\begin{array}{c}9.8 \\
(1.3)\end{array}$ & $\begin{array}{l}16.4 \\
(2.1)\end{array}$ & $\begin{array}{l}10.5 \\
(1.4)\end{array}$ & $\begin{array}{c}0.0 \\
(0.0)\end{array}$ \\
\hline 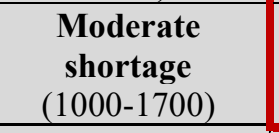 & $\begin{array}{c}7.5 \\
(1.0)\end{array}$ & $\begin{array}{l}35.6 \\
(4.6)\end{array}$ & $\begin{array}{l}110.8 \\
(14.4)\end{array}$ & $\begin{array}{l}37.5 \\
(4.9)\end{array}$ & $\begin{array}{c}0.0 \\
(0.0)\end{array}$ \\
\hline $\begin{array}{l}\text { Near shortage } \\
(1000-10000)\end{array}$ & $\begin{array}{c}1.8 \\
(0.2)\end{array}$ & $\begin{array}{l}42.2 \\
(5.5)\end{array}$ & $\begin{array}{l}160.9 \\
(20.9)\end{array}$ & $\begin{array}{l}134.7 \\
(17.5)\end{array}$ & $\begin{array}{c}1.2 \\
(0.2)\end{array}$ \\
\hline $\begin{array}{c}\text { No shortage } \\
(>10000)\end{array}$ & $\begin{array}{c}0.0 \\
(0.0)\end{array}$ & $\begin{array}{l}15.0 \\
(1.9)\end{array}$ & $\begin{array}{l}74.5 \\
(9.7) \\
\end{array}$ & $\begin{array}{l}24.9 \\
(3.2) \\
\end{array}$ & $\begin{array}{c}1.0 \\
(0.1) \\
\end{array}$ \\
\hline No Data & $\begin{array}{c}0.0 \\
(0.0)\end{array}$ & $\begin{array}{c}0.1 \\
(0.0) \\
\end{array}$ & $\begin{array}{c}0.2 \\
(0.0) \\
\end{array}$ & $\begin{array}{c}0.0 \\
(0.0)\end{array}$ & $\begin{array}{c}0.0 \\
(0.0)\end{array}$ \\
\hline
\end{tabular}


1024 Supplementary Table 3: Global crop production distribution, measured in calories, relative to 1025 water availability trends and categorized by allocated end use.

\begin{tabular}{|c|c|c|c|c|c|}
\hline $\begin{array}{c}\text { Crop } \\
\text { allocation }\end{array}$ & $\begin{array}{c}\text { Severe } \\
\text { drying } \\
\left(10^{14} \mathrm{kcal}\right)\end{array}$ & $\begin{array}{c}\text { Moderate } \\
\text { drying } \\
\left(10^{14} \mathrm{kcal}\right)\end{array}$ & $\begin{array}{c}\text { Static } \\
\text { conditions } \\
\left(10^{14} \mathrm{kcal}\right)\end{array}$ & $\begin{array}{c}\text { Moderate } \\
\text { wetting } \\
\left(10^{14} \mathrm{kcal}\right)\end{array}$ & $\begin{array}{c}\text { Severe } \\
\text { wetting } \\
\left(10^{14} \mathrm{kcal}\right)\end{array}$ \\
\hline Human food & 3.0 & 10.4 & 23.7 & 12.3 & 0.2 \\
$(6 \%)$ & $(21 \%)$ & $(48 \%)$ & $(25 \%)$ & $(<1 \%)$ \\
\hline Animal feed & 0.2 & 5.4 & 15.4 & 12.6 & 0.1 \\
$(<1 \%)$ & $(16 \%)$ & $(46 \%)$ & $(37 \%)$ & $(<1 \%)$ \\
\hline Nonfood use & 0.2 & 1.5 & 3.8 & 2.2 & 0.0 \\
& $(2 \%)$ & $(19 \%)$ & $(50 \%)$ & $(29 \%)$ & $(<1 \%)$ \\
\hline \multirow{2}{*}{ Total } & 3.4 & 17.3 & 43.0 & 27.1 & 0.3 \\
& $(4 \%)$ & $(19 \%)$ & $(47 \%)$ & $(30 \%)$ & $(<1 \%)$ \\
\hline
\end{tabular}


1026 Supplementary Table 4: TWS trend uncertainty for the 34 regional trends assessed in Rodell et 1027 $\mathrm{al}^{1}$, and converted to in mmyr ${ }^{-1}$ assuming a constant water density of $999.7 \mathrm{kgm}^{-3}$.

\begin{tabular}{|c|c|c|c|c|c|}
\hline ID & Location & $\begin{array}{l}\text { Area } \\
\left(\mathbf{k m}^{2}\right)\end{array}$ & $\begin{array}{c}\text { TWS trend } \\
\left(\mathrm{Gtyr}^{-1}\right)\end{array}$ & $\begin{array}{l}\text { TWS trend } \\
\text { error }\left(G_{t y r}^{-1}\right)\end{array}$ & $\begin{array}{c}\text { TWS trend error } \\
\left(\mathrm{mmyr}^{-1}\right)\end{array}$ \\
\hline 1 & Antarctica & 12397401 & -127.6 & 39.9 & 3.2 \\
\hline 2 & Greenland & 2184307 & -279 & 23.2 & 10.6 \\
\hline 3 & Gulf of Alaska coast & 716492 & -62.6 & 8.2 & 11.4 \\
\hline 4 & Canadian Archipelago & 672413 & -74.6 & 4.1 & 6.1 \\
\hline 5 & Northern North America & 1350129 & 6.1 & 5.8 & 4.3 \\
\hline 6 & Northern Eurasia & 8009175 & 13.4 & 9.7 & 1.2 \\
\hline 7 & Northern India & 664169 & -19.2 & 1.1 & 1.7 \\
\hline 8 & Central India & 1352670 & 9.4 & 0.6 & 0.4 \\
\hline 9 & Eastern Central China & 657375 & 7.8 & 1.6 & 2.4 \\
\hline 10 & Tibetan Plateau & 881704 & 7.7 & 1.4 & 1.6 \\
\hline 11 & Northwestern China & 215152 & -5.5 & 0.5 & 2.3 \\
\hline 12 & North China Plain & 876004 & -11.3 & 1.3 & 1.5 \\
\hline 13 & Eastern India Region & 1228839 & -23.3 & 1.9 & 1.5 \\
\hline 14 & Northwestern Saudi Arabia & 841763 & -10.5 & 1.5 & 1.8 \\
\hline 15 & Northern Middle East & 2189561 & -32.1 & 1.5 & 0.7 \\
\hline 16 & Southwestern Russia Region & 1772712 & -18.1 & 1.3 & 0.7 \\
\hline 17 & Aral Sea & 52299 & -2.2 & 0.1 & 1.9 \\
\hline 18 & Caspian Sea & 377761 & -23.7 & 4.2 & 11.1 \\
\hline 19 & Central Canada & 802682 & -7 & 6.4 & 8.0 \\
\hline 20 & Northern Great Plains & 1333598 & 20.2 & 4.8 & 3.6 \\
\hline 21 & Southern California & 177996 & -4.2 & 0.4 & 2.2 \\
\hline 22 & $\begin{array}{c}\text { Southern High Plains and } \\
\text { eastern Texas }\end{array}$ & 1105113 & -12.2 & 3.6 & 3.3 \\
\hline 23 & Patagonian ice fields & 461198 & -25.7 & 5.1 & 11.1 \\
\hline 24 & Central Argentina & 530661 & -8.6 & 1.2 & 2.3 \\
\hline 25 & Central and western Brazil & 5559805 & 51.9 & 9.4 & 1.7 \\
\hline 26 & Eastern Brazil & 1132450 & -16.7 & 2.9 & 2.6 \\
\hline 27 & Okavango Delta & 1589692 & 29.5 & 3.5 & 2.2 \\
\hline 28 & Nile headwaters & 1824276 & 21.9 & 3.9 & 2.1 \\
\hline 29 & Tropical western Africa & 2298134 & 24.1 & 2.1 & 0.9 \\
\hline 30 & Northern Congo & 1318261 & -7.2 & 1 & 0.8 \\
\hline 31 & Southeastern Africa & 1677719 & -12.9 & 2.3 & 1.4 \\
\hline 32 & Northern Africa & 6664135 & -11.7 & 2.9 & 0.4 \\
\hline 33 & $\begin{array}{c}\text { Northern \& Eastern } \\
\text { Australia }\end{array}$ & 2504494 & 19 & 2.8 & 1.1 \\
\hline 34 & Northwestern Australia & 1002367 & -8.9 & 1.2 & 1.2 \\
\hline \multicolumn{5}{|c|}{ Mean (area weighted mean) } & $3.2(2.4)$ \\
\hline
\end{tabular}


1028 Supplementary Table 5: TWS trend uncertainty for a subset of 41 river basins assessed in 1029 Scanlon et al. ${ }^{25}$, and converted to $\mathrm{mmyr}^{-1}$ units.

\begin{tabular}{|c|c|c|c|c|}
\hline No. & River & $\begin{array}{c}\text { Area } \\
\left(10^{6} \mathbf{k m}^{2}\right)\end{array}$ & Combined uncertainty $\left(\mathrm{km}^{3} \mathrm{yr}^{-1}\right)$ & $\begin{array}{c}\text { TWS trend error } \\
\left(\mathrm{mmyr}^{-1}\right)\end{array}$ \\
\hline 1 & Ganges & 1.03 & 3 & 2.91 \\
\hline 2 & Euphrates & 0.76 & 2.1 & 2.76 \\
\hline 3 & Brahmaputra & 0.66 & 1.2 & 1.82 \\
\hline 4 & Indus & 0.97 & 1.3 & 1.34 \\
\hline 5 & Volga & 1.41 & 1.1 & 0.78 \\
\hline 6 & Arkansas & 0.67 & 1 & 1.49 \\
\hline 7 & Sao Francisco & 0.61 & 1.2 & 1.97 \\
\hline 8 & Don & 0.42 & 1 & 2.38 \\
\hline 9 & Huanghe & 0.79 & 0.5 & 0.63 \\
\hline 10 & $\mathrm{Ob}$ & 3 & 0.4 & 0.13 \\
\hline 11 & Tamanrasset & 1.76 & 0.4 & 0.23 \\
\hline 12 & Rio Grande & 0.62 & 0.6 & 0.97 \\
\hline 13 & Syr Darya & 0.42 & 0.4 & 0.95 \\
\hline 14 & Thelon & 0.14 & 0.7 & 5 \\
\hline 15 & Amu Darya & 0.49 & 0.2 & 0.41 \\
\hline 16 & MacKenzie & 1.74 & 1.8 & 1.03 \\
\hline 17 & Brazos & 0.13 & 0.5 & 3.85 \\
\hline 18 & Hai & 0.16 & 0.4 & 2.5 \\
\hline 19 & Colorado & 0.12 & 0.5 & 4.17 \\
\hline 20 & Huaihe & 0.22 & 0.4 & 1.82 \\
\hline 21 & Tarim & 0.44 & 0.9 & 2.05 \\
\hline 22 & Amazon & 6.23 & 1.5 & 0.24 \\
\hline 23 & Zambezi & 1.34 & 1.3 & 0.97 \\
\hline 24 & Okovango & 0.79 & 2.5 & 3.16 \\
\hline 25 & Niger & 2.12 & 1 & 0.47 \\
\hline 26 & Mississippi & 3.25 & 6 & 1.85 \\
\hline 27 & Amur & 1.87 & 0.4 & 0.21 \\
\hline 28 & Parana & 2.99 & 4.7 & 1.57 \\
\hline 29 & Orinoco & 0.91 & 1.3 & 1.43 \\
\hline 30 & Columbia & 0.72 & 0.5 & 0.69 \\
\hline 31 & Murray & 1.07 & 2 & 1.87 \\
\hline 32 & Yangtze & 1.73 & 3 & 1.73 \\
\hline 33 & Volta & 0.38 & 0.5 & 1.32 \\
\hline 34 & Nile & 2.98 & 8.9 & 2.99 \\
\hline 35 & Yenisei & 2.61 & 0.5 & 0.19 \\
\hline 36 & Missouri & 1.38 & 0.4 & 0.29 \\
\hline 37 & Kolyma & 0.64 & 0.6 & 0.94 \\
\hline 38 & Orange & 1 & 1.5 & 1.5 \\
\hline 39 & St. Lawrence & 1.11 & 0.7 & 0.63 \\
\hline 40 & Lena & 2.35 & 2.4 & 1.02 \\
\hline \multirow[t]{2}{*}{41} & Godavari & 0.33 & 0.5 & 1.52 \\
\hline & & & Mean (area weighted mean) & $1.6(1.1)$ \\
\hline
\end{tabular}




\section{SI-3. Author contributions}

1030 The idea for the paper was conceived by X.H. with input from T.G., S.C.Z., and J.F. Analyses 1031 were conducted by X.H. The manuscript was written by X.H. with input from all authors. 